IZA DP No. 7222

Stayers and Returners: Educational Self-Selection among U.S. Immigrants and Returning Migrants

Arturo A. Aguilar Esteva

February 2013 


\title{
Stayers and Returners: Educational Self-Selection among U.S. Immigrants and Returning Migrants
}

\author{
Arturo A. Aguilar Esteva \\ ITAM and IZA \\ Discussion Paper No. 7222 \\ February 2013 \\ IZA \\ P.O. Box 7240 \\ 53072 Bonn \\ Germany \\ Phone: +49-228-3894-0 \\ Fax: +49-228-3894-180 \\ E-mail: iza@iza.org
}

\begin{abstract}
Any opinions expressed here are those of the author(s) and not those of IZA. Research published in this series may include views on policy, but the institute itself takes no institutional policy positions. The IZA research network is committed to the IZA Guiding Principles of Research Integrity.

The Institute for the Study of Labor (IZA) in Bonn is a local and virtual international research center and a place of communication between science, politics and business. IZA is an independent nonprofit organization supported by Deutsche Post Foundation. The center is associated with the University of Bonn and offers a stimulating research environment through its international network, workshops and conferences, data service, project support, research visits and doctoral program. IZA engages in (i) original and internationally competitive research in all fields of labor economics, (ii) development of policy concepts, and (iii) dissemination of research results and concepts to the interested public.
\end{abstract}

IZA Discussion Papers often represent preliminary work and are circulated to encourage discussion. Citation of such a paper should account for its provisional character. A revised version may be available directly from the author. 


\section{ABSTRACT \\ Stayers and Returners: Educational Self-Selection among U.S. Immigrants and Returning Migrants ${ }^{*}$}

This paper empirically examines the educational selectivity of United States immigrants and of those that return to their source country. Data from the 1970 to 2000 U.S. Census and the 2010 American Community Survey are employed. Ten countries are selected for the study based on their historical and contemporaneous importance on U.S. migration. The results generally indicate positive selection on educational attainment of recently-arrived immigrants, being China, India, and Philippines the most prominent examples. Mexico does not show evidence of positive or negative selection, but their immigrants' selectivity has worsened through time. Historically, the educational selectivity of returning migrants accentuated the positive selection of those migrants that stay in the United States in most countries' cases. However, patterns of selection among migrants that stay have recently changed. A more detailed analysis with data from the last decade finds evidence of positive selection of immigrants staying in the U.S. for the Mexican and Philippines' case, as well as negative selection for the Chinese. Trends of returning migration are also analyzed by gender, age, naturalization status, and migration spell duration. Mixed evidence of selection trends is found.

JEL Classification: $\quad$ I25, J11, J61

Keywords: immigration, return migration, self-selection, education

Corresponding author:

Arturo A. Aguilar Esteva

Department of Economics

ITAM

Mexico City 10700

Mexico

E-mail: arturo.aguilar@itam.mx

\footnotetext{
* I am grateful for the suggestions given by Richard Alba, Larry Katz, Mary Waters, and seminar participants at Harvard University and the Harvard-Manchester workshop. All errors are my own.
} 


\section{Introduction}

The dynamics of immigration and return migration flows influence the composition of the recipient country's population. Therefore, countries with an important immigrant population presence ${ }^{1}$ care about their immigrant's characteristics. This problem has motivated research work that analyzes the patterns of immigrants' selection and its effects on different economic dimensions (Carliner 1980; Chiswick 1978; Borjas 1987, 1999; Dustmann et al. 2011).

This paper contributes to the literature by empirically analyzing from a historical perspective the selectivity that immigrants and returning migrants exhibit in terms of schooling. The historical component makes possible not only to analyze the types of self-selection of immigrants and return migrants, but also how this selection has evolved. The United States is considered to be the host country and a group of ten sending countries are selected based on their historical contribution towards migration. Immigrant selectivity is described by comparing recently arrived immigrants schooling distribution with respect to that of their home country's population. Return migrants' selectivity is identified through sample attrition. Synthetic cohorts are followed through census years to analyze changes in the schooling distribution. Finally, trends of return migrant selection during the last decade are estimated with greater detail using kernel density comparisons and more disaggregated schooling information.

From a microeconomic point of view, migration has been studied as a rational choice made by maximizing agents. The literature began by identifying migrants as a group of individuals that share some characteristics, like being more ambitious, highly motivated, and hard-working (Carliner 1980; Chiswick 1978). Some years later, in one of the most influential theoretical papers written on the topic, Borjas $(1987,1991)$ developed an application of Roy's model (Roy 1951) to explain how migrants self-select from the source country's income distribution. According to that model, immigrants arriving from a coun-

\footnotetext{
${ }^{1}$ The most recent figures indicate that the U.S comprises 42.8 million immigrants (13.5\% of its population). In terms of number of immigrants it is followed by Russia, Germany, Saudi Arabia and France (Koser and Laczko 2010).
} 
try that has a higher (lower) level of inequality with respect to the host country, ${ }^{2}$ would negatively (positively) select from the source country's income distribution.

In a later paper, Borjas and Bratsberg (1996) extended the Borjas $(1987,1991)$ model to account for migrants returning to their country of origin. They concluded that return migration accentuates the kind of selection that results from immigration. This conclusion is relevant from a political point of view for countries such as the U.S., which has seen a recent wave of immigration from countries with higher levels of inequality (like Mexico and Central American countries). According to these models, the immigrants arriving to the U.S. from these countries would be drawn from the bottom of the income distribution of their home population. Moreover, the immigrants that decide to return to their home countries would be drawn from the top of the income distribution of the immigrant population. This would leave in the U.S. a group of permanent migrants even more negatively selected in terms of skills (see Borjas and Bratsberg (1996), pp. 167, Figure 2, for a clear illustration of this idea).

Some later work contested these results. Chiquiar and Hanson (2005) developed an extension of the Borjas (1991) model. They showed that if the costs of migration decline with education, then the patterns of selection might be affected. More recently, Dustmann et al. (2011) developed a model that distinguishes between two types of "skills." Their idea is to capture that some countries are "learning centers," and that the experience gained in those countries is valuable in the host country. They concluded that immigration and return migration patterns need not to be either positively or negatively selected.

Regarding the empirical literature, there is work both consistent and inconsistent with the Borjas (1987, 1991) selection models. Recently, Fernández-Huertas Moraga (2011) and Ambrosini and Peri (2012) found evidence of Mexican immigrants' negative selection in support of this result. Chiquiar and Hanson (2005) argued that Mexican migrants are selected from the middle and upper section of Mexicans' wage densities. Other papers that tested the selection models include: Akee (2007), Borjas and Friedberg (2009), Feliciano

\footnotetext{
${ }^{2}$ The higher (lower) level of inequality is used as an indicator of higher (lower) returns to skills.
} 
(2005), Hanson (2007), Ibarraran and Lubotsky (2007), Kaestner and Malamud (2010), and Orrenius and Zavodny (2005).

Nevertheless, little empirical work has been done concerning return migration. Borjas (1989) infers that return migration could be estimated by sample attrition using a longitudinal data set. Employing a sample of foreign-born scientists and engineers he finds that there is evidence that supports positive selection of returning migrants (i.e. the least successful leave the country). Jasso and Rosenzweig (1988) assume that migrants who do not naturalize are more likely to return to their countries, and show that the more skilled do not naturalize. Coulon and Piracha (2005) find that returning migrants to Albania are negatively selected from the country's earnings distribution. More recently, Ambrosini and Peri (2012) find positive selection of Mexican returning migrants, both in terms of observable and unobservable characteristics using a longitudinal Mexican dataset.

The data used in this paper comes from the 1970-2010 Integrated Public Use Microdata Samples (IPUMS) of the 1970 to 2000 U.S. Census, as well as the 2010 American Community Survey (ACS) (Ruggles et al. 2010). The ten source countries considered include: Canada, Central America, ${ }^{3}$ China, Dominican Republic, England, Germany, India, Italy, Mexico, and Philippines. These countries were selected for their historical and contemporaneous importance as migrant-source populations in the U.S. Also, it was essential to include countries that had both higher and lower levels of inequality (and returns to education) to compare the results with the predictions of selection models in the literature.

The methodology employed in this paper consisted of the following. First, to assess immigrant selection, the source country's educational distribution ${ }^{4}$ is compared to that of same-aged recently arrived U.S. immigrants. Immigrants just-arrived are identified at each U.S. census as those that report "first entering to stay in the U.S." within the last 5 years. Then, to estimate the return migration selection, synthetic cohorts are formed using the country of birth, age and "year of first entry to stay in the U.S." questions. It

\footnotetext{
${ }^{3}$ Includes Belize, Costa Rica, El Salvador, Guatemala, Honduras, Nicaragua, and Panama.

${ }^{4}$ The source country education distribution data is obtained from the Barro and Lee (2010) longitudinal dataset of educational attainment by age groups.
} 
is assumed that changes in the education distribution of a given cohort through time are mostly explained by return migration. Given that the Census and ACS are cross-section datasets, the key assumption is that each given cohort is comparable through time. Finally, return migration trends during the last decade are analyzed in greater detail. Kernel density estimations of the 2000 and 2010 schooling distributions are compared. ${ }^{5}$ Selectivity patterns are analyzed in terms of gender, age, naturalization, and migration spell duration.

The analysis provides evidence of positive selection of immigrants. Interestingly, the positive selectivity of migrants has increased through time. This result is partly due to source countries' schooling improvements, but in some cases the increase in positive selectivity exceeds the source countries' progress. China, India, and Philippines are the most prominent examples of positive immigrant selection with respect to the non-migrant population's schooling distribution. Contrastingly, Mexico and Central America's positive selection has declined and in the case of Mexico, there is no evidence of positive selection in recent migration cohorts. No evidence of negative selection of immigrants was found for any country analyzed.

With respect to return migration, the historical analysis shows that most of the countries' early migration cohorts (i.e. those arrived 1965-1970 and 1975-1980) exhibited positive selection of immigrants staying in the United States. However, this trend has declined for later migration cohorts and, in some cases, the positive selectivity has even disappeared. The more detailed analysis with data from the last decade finds that Mexico, the highest contributor of U.S. immigrants, exhibits a positive selection of migrants that stay in the U.S., although not as sharp as other source countries. Immigrants that stay are mostly those with high school degrees, while schooling levels below high school are dominated by the returning migrants. China, one of the highest immigrant growing country during the last decade exhibits negative selection for recently arrived cohorts. Immigrants with bachelor degrees tend to leave, while those with high school or less stay in the U.S. Philippines is the most notable case of positive selection of immigrants that stay.

\footnotetext{
${ }^{5}$ The data for the 2000 Census and 2010 ACS allows to observe greater detail of schooling acquisition than in the previous Census years.
} 
The remainder of the paper is organized as follows: Section 2 revises the theoretical framework that will guide the discussion; Section 3 gives a brief background on U.S. migration and explains how the countries for the present analysis were chosen; Section 4 describes the data used; Section 5 presents the empirical results; finally, Section 6 concludes.

\section{Theoretical framework}

The following model is based on the Borjas and Bratsberg (1996) theoretical framework and draws some of the components used by Chiquiar and Hanson (2005) in their extension of the Borjas (1991) model.

The main equations of the model indicate: (1) the income level that a person would receive in the source country, (2) the income level that he would receive in the host country, and (3) the income level that he would receive as a temporary migrant (i.e. migrating and then returning to the source country).

$$
\begin{aligned}
& \log w_{0 i}=\mu_{0}+\theta_{0} s_{i} \\
& \log w_{1 i}=\mu_{1}+\theta_{1} s_{i} \\
& \log w_{2 i}=\lambda_{i}\left(\mu_{1}+\theta_{1} s_{i}\right)+\left(1-\lambda_{i}\right)\left(\mu_{0}+\theta_{0} s_{i}+\kappa\left(s_{i}\right)\right)
\end{aligned}
$$

where, the sub-indexes relate to the country of reference, being " 0 " the sub-index for the country of origin, "1" the sub-index for the host country, and " 2 " the sub-index that indicates temporary migration; $w_{j i}$ refers to wages in country $j$ of individual $i ; \mu_{j}$ is the base wage; $\theta_{j}$ represents the returns to schooling; and $s_{i}$ denotes the level of schooling of individual $i$. Finally, the function $\kappa\left(s_{i}\right)$ represents the gains that an individual with schooling $s_{i}$ has on its income once he returns to his home country after migrating for $\lambda_{i}$ proportion of time. ${ }^{6}$

\footnotetext{
${ }^{6}$ For the time being, the form of the $\kappa(\cdot)$ function is not restricted. A more general version of the model would have the time spent abroad $\left(\lambda_{i}\right)$ as an input of the gain function: $\kappa\left(s_{i}, \lambda_{i}\right)$.
} 
Borjas and Bratsberg (1996) assume that the gains from migration for returning migrants on their home-country wages, $\kappa\left(s_{i}\right)$, are constant. There is evidence from the literature that sustains that experience gained during a migration spell might have superior returns to those gained in the host country. ${ }^{7}$ For example, Reinhold and Thom (2009) find that Mexicans who gained experience in the U.S. increased earnings more than twice compared to experience gained in Mexico. Similarly, for Irish migrants, Barrett and O'Connell (2001) find a wage premium for migration upon returning that is higher for people with post-graduate degrees.

Finally, the model includes two types of cost of migration: (i) the cost of immigrating to the U.S., $\psi_{M}\left(s_{i}\right)$; and (ii) the cost of returning to the country of origin, $\psi_{R}\left(s_{i}\right)$.

In this model, an individual will define his residence status by choosing the maximum level among three possible options: never migrate, migrate permanently, and migrate temporally. For this model, the alternative of several temporary migrations is left out. The optimization decision can be represented by the following maximization problem:

$$
\text { Income }_{i}=\max \left(\ln w_{0}, \ln w_{1}-\psi_{M}\left(s_{i}\right), \ln w_{2}-\psi_{M}\left(s_{i}\right)-\psi_{R}\left(s_{i}\right)\right)
$$

So far, an important assumption in the model is the linearity of the returns to schooling in the log income equations for non-migrants, permanent, and temporary migrants (equations [1] to [3]). Therefore, what determines the type of selection with respect to schooling is the functional form for gains from migration, $\kappa\left(s_{i}\right)$, and costs of migration $\psi_{M}\left(s_{i}\right)$ and $\psi_{R}\left(s_{i}\right)$, the schooling returns' parameters $\left(\theta_{j}\right)$ and the base wages $\left(\mu_{j}\right)$.

To illustrate the use of the model assume, as in Borjas and Bratsberg (1996), that the gains and costs of migration components are fixed $\left(\psi_{M}\left(s_{i}\right)=\psi_{1}, \psi_{R}\left(s_{i}\right)=\psi_{2}, \kappa\left(s_{i}\right)=\bar{\kappa}\right)$. This implies that all the alternatives in the maximization problem represented in equation [4] are linear with respect to schooling. Also, assume that immigrants arrive from a country with lower returns to schooling than those of the host country, then $\theta_{0}>\theta_{1}$. For temporary

\footnotetext{
${ }^{7}$ Some recent papers that provide evidence of this include: Barrett and Goggin (2010), Barrett and O'Connell (2001), Co et al. (2000), and Iara (2006).
} 
migration to be an optimal decision, it has to be the case that the gains from migration dominate the costs of migrating and re-migrating. ${ }^{8}$ Figure 1 illustrates the maximization decision under the assumption that temporary migration is an optimal enterprise for some individuals. It shows how negative selection of immigrants results and how the alternative of returning migration accentuates the self-selection outcome. If returning migration was not considered, individuals below $s^{*}$ would migrate and those above $s^{*}$ would stay in their home country. After adding the return migration option, the individuals below $s_{1}$ decide to permanently migrate, those between $s_{1}$ and $s_{2}$ migrate temporally, and those above $s_{2}$ stay in their home country. As a result, permanent immigrants are an even more negatively selected group than without return migration (i.e. it can be easily shown formally that $\left.s_{1}<s^{*}\right)$.

\section{[Insert Figure 1 here]}

Using this general model, it is possible to show that a different structure of the gains from migration and costs functions could yield different patterns of self-selection. ${ }^{9}$ For instance, let $\kappa^{\prime} \leq 0$ and $\kappa^{\prime \prime} \geq 0$, that is, let the individuals with less schooling benefit more from their experience gained during their migration spell. Also, let $\psi_{M}^{\prime}<0, \psi_{R}^{\prime}<0$, $\psi_{M}^{\prime \prime}>0$, and $\psi_{R}^{\prime \prime}>0$, that is, let the costs be a decreasing and convex function of schooling. In this case, the negative selection outcome could be overturned. To illustrate this argument in a simplified way, let the migrations cost functions be:

$$
\begin{gathered}
\psi_{M}\left(s_{i}\right)=\exp \left(\alpha_{M}-\phi_{M} s_{i}\right) \\
\psi_{R}\left(s_{i}\right)=\exp \left(\alpha_{R}-\phi_{R} s_{i}\right)
\end{gathered}
$$

Furthermore, let the gains from migration be positive and constant for those individuals with schooling below $\hat{s}$, and zero for those above. Then, the gains function would be:

$$
\kappa\left(s_{i}\right)=\bar{\kappa} \cdot 1\left\{s_{i}<\hat{s}\right\}, \bar{\kappa}>0
$$

\footnotetext{
${ }^{8}$ This condition is formalized in Borjas and Bratsberg (1996), pp. 167, equation (6)

${ }^{9}$ For instance, Chiquiar and Hanson (2005) show that if $\psi_{M}(\cdot)$ is a positive but decreasing function of $s$, under certain conditions, the negative selection of migrants might not result as Borjas $(1987,1991)$ predicts.
} 
Therefore, if the gains from migration on the home income are high enough to compensate the costs of returning migration, it might be the case that for a group of individuals with low schooling and for whom permanent migration was originally their dominating option, now would be inclined toward temporary migration. This scenario is illustrated in Figure 2. All individuals below $s_{1}$ would not migrate either permanently or temporally because they face very high costs of migrating. Those between $s_{1}$ and $\hat{s}$ would find it optimal to migrate temporally. This group benefits from the gains that migration yields on their home wages. Those with schooling between $\hat{s}$ and $s_{2}$ would have a tendency towards permanent migration. This group no longer receives high enough gains from migration (none in this simplified case) to overcome the costs they have to pay for returning home. Finally, the group above $s_{2}$ remains at home. In this example, the observed self-selection pattern would depend on the support of the schooling distribution for the population in the source country.

\section{[Insert Figure 2 here]}

By no means this is a general result. As described above, it is relevant to note that the self-selection pattern depends entirely on the relation that costs and gains of migration have with the skills of the individuals. This relation might even be distinct between differ-

ent kinds of source and host countries. For instance, the immigrants in the U.S. might get different gains from temporary migration if they arrived from Canada or Central America.

It is also important to mention that the model leaves out features that have been mentioned in the literature as having direct influence in the costs and gains from migration. For example, migration networks might have a direct implication in the costs of migration, and uncertainty over the outcome of migration might affect gains.

\section{Selected countries for the analysis}

The United States is, by far, the country that hosts most migrants in the world. The latest figures indicate that more than 40 million immigrants inhabit in the U.S. (Koser and Laczko 2010). Since the end of World War II, the trend of legal immigrants admitted 
in the U.S. has been increasing. Recently, in 2010, 1.04 million legal immigrants were admitted (Department of Homeland Security 2012). In addition to this, illegal immigration contributes to this numbers in a significant way as well. The latest figures estimate the illegal population around 11.2 million (Passel and Cohn 2010).

In this paper, ten different countries were chosen to analyze the selection patterns in terms of schooling that their immigrant and returning migrant populations exhibit: Canada, Central America (Belize, Costa Rica, El Salvador, Guatemala, Honduras, Nicaragua, and Panama), China, Dominican Republic, England, Germany, India, Italy, Mexico, and Philippines (see Figure 3).

[Insert Figure 3 here]

The following conditions were used to guide the selection of the countries for the study:

a) Countries with important immigrant presence in the U.S. From a practical perspective, it is relevant to know the characteristics of the population that contribute the most in absolute numbers to migration. From a methodological perspective, getting sufficient observations in the samples favors statistical validity. Table 1 shows the top ten ranked countries in terms of number of migrants in the U.S. from 1970 to 2010. The countries that were top ranked in that list at some point were selected.

[Insert Table 1 here]

\section{b) Countries with both higher and lower levels of inequality (or human capital} returns) than the U.S. Given the theoretical framework specified in Section 2, this information would predict if $\theta_{0} \gtrless \theta_{1}$. If the cost and gain functions are assumed to be fixed, then this information should be sufficient to predict the patterns of self-selection in terms of schooling. Figure 4 shows the difference of the GINI coefficient between the U.S. and the selected countries whenever possible (United Nations 2008). ${ }^{10}$ Ad-

\footnotetext{
${ }^{10}$ The dataset used for this comparison is the WIID2b from the United Nations. This dataset collects information from national surveys. In particular, the income definitions used to construct the GINI coefficients are usually different among countries. The WIID2b database pays special attention to this problem to favor comparability among countries. For more information see: http://www.wider.unu.edu/research/ Database/en_GB/database
} 
ditionally, Figure 5 shows the difference in the returns to schooling between the U.S. and the selected group of countries, whenever the data was available. ${ }^{11}$

[Insert Figures 4 and 5 here]

c) Geography. A natural choice was to select the two U.S. bordering countries: Canada and Mexico. In addition to being both bordering countries, they have the opposite relation with respect to the U.S. in terms of inequality. Hence, it would be interesting to compare their immigrants patterns of selection in terms of schooling. Central America and the Dominican Republic are the next set of countries in terms of proximity. Additionally, their levels of inequality might make a comparable case to Mexican migration. The Central American countries share borders, similar levels of inequality and schooling distribution within each other, hence they were grouped for analysis.

\section{Data and empirical strategy}

The data used in this paper comes from two main sources:

Barro and Lee (2010). The educational attainment from the source countries comes from the Barro and Lee (2010) panel dataset (B\&L hereafter). This is a longitudinal dataset on educational attainment that covers 146 countries from 1950 to 2010. The information is provided every 5 years and each country's population is disaggregated by gender and age groups (in 5-year intervals). All the countries chosen for the analysis have available information. Educational attainment is classified in seven categories: (i) no schooling; (ii) primary incomplete; (iii) primary complete; (iv) secondary incomplete; (v) secondary complete; (vi) tertiary incomplete; and (vii) tertiary complete.

The B\&L dataset was constructed with the specific purpose of cross-country comparisons and has been constantly been updated and improved. See Barro and Lee (2010) for further details.

\footnotetext{
${ }^{11}$ The data for returns to schooling comes from Psacharopoulos and Patrinos (2002)
} 
Integrated Public Use Microdata Samples (IPUMS). The U.S. 1970-2000 U.S. decennial Census 5\% samples (except for 1970, where the 1\% Form 1 State sample was the most appropriate), and the 2010 American Community Survey (ACS) are used in the analysis. The analysis presented here will use individual information about school attainment, immigrants' country of birth, first year of entry to stay in the U.S., citizenship status, and labor market indicators. The analysis is restricted to individuals not living in group quarters, that report being in the labor force, with positive individual income during the previous year, inhabiting in the continental U.S. territory. ${ }^{12}$

The methodology followed to identify immigrant and return migrants selection consisted on the following:

Identification of immigrant selection. At each census, a group of recently arrived immigrants are identified as those individuals born in a foreign country that report first entering to stay in the U.S. within the previous five years (e.g. in the case of the 1970 census, a recent arrived immigrant would have entered the U.S. between 1965 and 1970 for the first time). ${ }^{13}$ It is assumed that individuals report their first entrance to the United States with the purpose of inhabiting there and not for temporary stays (like vacation or family visits).

To identify immigrant selection, the schooling distribution of recently arrived immigrants is compared to that of the same-aged population from their source country at each census. The source country schooling distribution comes from the B\&L dataset. To match the schooling attainment categories available form the B\&L dataset, a standardized variable of school attainment is generated using the categories available at the census datasets. Table A.2 in the Appendix details how the standardized educational variable was formed using the schooling categories available at the different census years.

\footnotetext{
${ }^{12}$ Those individuals with total personal income below the 1st percentile or above the 99th percentile are excluded to avoid outliers. Those living in Hawaii or Alaska are also excluded since migration trends might be different to those locations.

${ }^{13}$ The 1970, 1980, and 1990 census asked when the person first came to stay in the U.S.; the 2000 census and the ACS asked when the person first came to live in the United States.
} 
Identification of return migrant selection. Recently arrived migrants are followed through the different census years by using synthetic cohorts. The cohorts are defined based on the country of birth, age, and "first year of entry to stay in the U.S." Each cohort is followed through three census years. Ages are restricted to recently arrived migrants over 30 to avoid individuals that migrate to the U.S. and acquire additional education while in the U.S. Also, ages are restricted below 65 at the last cohort follow-up. The following table gives a clear illustration of how the cohorts are formed: ${ }^{14}$

\section{Cohort definitions}

\begin{tabular}{|c|c|ccccc|}
\hline & Year of Entry & \multicolumn{5}{|c|}{ Ages } \\
\cline { 3 - 7 } Cohort & to the U.S. & 1970 & 1980 & 1990 & 2000 & 2010 \\
\hline 1 & $1965-1970$ & $30-45$ & $40-55$ & $50-65$ & & \\
2 & $1975-1980$ & & $30-45$ & $40-55$ & $50-65$ & \\
3 & $1985-1990$ & & & $30-45$ & $40-55$ & $50-65$ \\
4 & $1995-2000$ & & & & $30-45$ & $40-55$ \\
\hline
\end{tabular}

To identify the selection in terms of schooling of return migrants, the distribution of the educational attainment is compared for a given cohort through the different census years. The data is not longitudinal so the results should be interpreted as how does the schooling distribution changes for groups of people with similar baseline characteristics observed at different points in time. Differences in the distribution are assumed to be mainly the result of migrants returning to their country of origin. Therefore, if a given cohort's schooling distribution reflects a more (less) educated group 10 or 20 years after the initial migration, it is assumed that the migrants that left were less (more) educated.

One concern from the analysis is that migrants might poorly report the "first year of entry to the U.S." question. More educated individuals might be more likely to have previously visited the U.S. if they are from a foreign country. As a result, they might be undercounted as recently arrived immigrants (1970, 1980 and 1990 census), but not in a follow-up where the text of the "first year of entry" question changed to explicitly include "first entry to live in the U.S." (after the 2000 census and the ACS). This might bias the

\footnotetext{
${ }^{14}$ Table A.1 in the Appendix indicates the number of observations for each cohort by census (or ACS) year and country of origin.
} 
analysis towards positive selection. Only the analysis of cohort 4 would not be affected by this potential bias.

Recent returning migration trends. A more detailed analysis of recent return migration trends is done with post-2000 data. Table A.2 in the Appendix indicates how a more disaggregated schooling variable is formed using the 2000 Census and the 2010 ACS schooling categories. The greater detail in the schooling variable makes possible to use a non-parametric kernel density estimation for the 2000 and 2010 distributions of schooling. ${ }^{15}$ This analysis will also distinguish the returning migration trends by gender, age, naturalization status, and migration duration spell (using the first year of entry).

Limitations. Other explanations to differences in the schooling distribution include: (i) migrants moving to other destinations (different form their country of origin); (ii) adults increasing their level of education during their migration spell; and (iii) deceased individuals. The age restriction attempts to leave out individuals that might migrate to the U.S. to acquire tertiary education (undergraduate or graduate level schooling), but this option cannot be disregarded, specially for graduate levels of study. This restriction will also reduce the positive selection of young immigrants that move to the U.S. to acquire graduate education and that might be likely to stay in the U.S. The empirical results provided most likely reflect selection patterns of individuals that had completed their schooling before moving to the U.S.

\section{Results}

The results presented in this section attempt to shed some light on three subjects: (i) historical selection patterns observed in terms of schooling for just-arrived immigrants compared to their same-aged home country population; (ii) historical selection patterns observed in

\footnotetext{
${ }^{15} \mathrm{~A}$ Gaussian kernel function is used in the estimations. Twice the Silverman rule of thumb that establishes a bandwidth equal to $h=2 * 1.06 \hat{\sigma} n^{-\frac{1}{5}}$ is used, where $\hat{\sigma}$ denotes the standard deviation and $n$ the number of observations for the schooling variable (Silverman 1986). Twice the optimal bandwidth is used with the purpose to over-smooth the density. The same conclusions result with the use of the optimal bandwidth.
} 
terms of schooling for permanent migrants with respect to migrants that left; and (iii) recent selection patterns in terms of schooling of returning immigrants distinguishing for gender, age, naturalization, and migration spell duration. Given the information about inequality and returns to education (Figures 4 and 5), it is also possible to evaluate to what extent are the predictions from the theoretical literature met. In addition, the evidence provided will give detailed information to analyze the patterns and trends of selection for each of the ten countries under study.

\subsection{Selection of immigrants}

To determine the pattern of selection of immigrants with respect to their home country's population, the schooling cumulative distribution function (hereafter CDF) of recently arrived immigrants is compared to that of their same-aged home-country's population. Figures $6 a$ to $6 j$ illustrate this comparison in a country-by-country basis for each of the cohorts previously defined. The bold line on each graph shows the schooling CDF of the source country's population with ages 30 to 45 , obtained from the B\&L dataset. The dashed line shows the schooling CDF of the "just-arrived" immigrant population aged 30 to 45. Finally, the gray line shows the schooling CDF of the latest follow-up available for each cohort. The comparison between the dashed and gray line will be used to assess the return migrants' selectivity. For example, in the first panel of Graph 6a (Cohort 1), the bold line shows the 1970's schooling CDF of the Canadian population 30-45 years old; the dashed line shows the 1970's schooling CDF of Canadian immigrants aged 30 to 45 who arrived to the U.S. between 1965 and 1970; and the gray line shows the 1990's schooling CDF of Canadian immigrants aged 50 to 65 that arrived to the U.S. between 1965 and 1970 .

[Insert Figures 6a to 6j here]

Whenever the home-country CDF first-order dominates the just-arrived immigrants' CDF, there would be evidence of negative selection. The first-order dominance would indicate that for any category of schooling, there would be a higher proportion of home country's population than just-arrived migrants with more or equal schooling. In the op- 
posite case, whenever the just-arrived migrants CDF first-order dominates, there would be evidence for positive selection.

Figures $6 a$ to $6 j$ provide overwhelming evidence of positive selection in terms of schooling for almost every cohort-country pair. China, India, and Philippines exhibit the largest differences between the source country and the recent immigrants' CDFs, being all cases of positive selection. For example, Figure $6 g$ shows that most of India's population attain levels of school achievement below complete secondary level. Nevertheless, over $80 \%$ of the migrants that arrive to the U.S. show the highest level of schooling (tertiary complete).

The positive selectivity of just-arrived immigrants is evident even for countries with higher levels of inequality and returns to schooling than the U.S. (like Central America and Dominican Republic). The only cases where there is no first-order domination of the immigrants' CDF are Italy (cohort 1) and Mexico (cohorts 2 to 4). However, none of these cases shows evidence of negative selectivity either. The case of Mexico is of particular interest, given that nowadays it is the main contributor of foreign-born population in the U.S. For the most recent immigration wave analyzed (immigrants arrived 1995-2000), $40 \%$ of the recently-arrived Mexican immigrants had levels of schooling below or equal to primary complete (Figure 6i). The only case that is close to this proportion is Central America (39\%), however, the Central America's schooling levels of the non-migrant population lags significantly below the Mexican.

Finally, the positive selectivity of just-arrived immigrants has increased through time, mainly because of the increase in the level of schooling at each source country. Still, in some cases the increase in positive selection of recently-arrived immigrants has exceeded the increase in their countries' level of schooling. For example, Canada, China, and Italy's positive selectivity increased through time, whereas Central America, Mexico, and Philippines decreased.

This evidence of positive selection is not particular for the age range used. Very similar results are obtained if the age range is expanded or reduced. It could be argued that 
the home-population distribution includes soon-to-be immigrants and returned migrants. However, for the argument of soon-to-be immigrants to overturn the result, it would have to be the case that immigrants with low levels of schooling make their migration decision rather late. Even if this was the case, a large number of individuals would be needed to overturn the result for most of the countries analyzed.

\subsection{Selection of returning migrants}

To determine the selection patterns that result from return migration, the synthetic cohorts are followed through time. As described above, the gray solid lines on Figures $6 a$ to $6 j$ represent the CDF for the population that remains in the U.S. 20 to 25 years after their initial immigration. To examine the return migration selection patterns, this CDF will be compared within each cohort to the CDF of the immigrants when they were recentlyarrived (the dashed line). Following the idea in Borjas (1989) that outmigration behavior can be inferred from sample attrition in a longitudinal data set of foreign-born scientists and engineers, it is assumed here that the main determinant of the difference between these CDFs is the population attrition originated by returning migrants.

If the CDF of the just-arrived immigrants (dashed line) first-order dominates the CDF of the immigrants that remain after several years (gray solid line), there would be evidence of negative selection of the immigrant population that stays in the U.S. On the contrary, if the CDF of the immigrants that remain first-order dominates, there would be evidence in favor of positive selection.

Most cases illustrated in Figures $6 a$ to $6 j$, suggest that positive selection in terms of schooling dominate in earlier cohorts (cohorts 1 and 2). Still, the positive selection magnitudes are not closely as sizeable as the immigrants' arrival selection. This positive selectivity usually disappears or at least is greatly reduced in recent cohorts (particularly cohort 4). Yet, there is very limited evidence of negative selection of staying migrants. The

evidence presented, paired with the levels of inequality and returns to education, is not consistent with the theoretical framework prediction with constant costs and gains from migration. 
The descriptive statistics also provides interesting insight (Table 2). In particular, it is notable that through time the proportion of males tends to decrease in all the countries' cases. This suggests that female's migration tends to be more permanent than male's. The individuals most successful to gain naturalization ten years after their initial arrival to the U.S. are from China, India, and Philippines, which on average achieve U.S. citizenship in $58 \%, 56 \%$, and $70 \%$ of the cases ten years after the initial immigration, respectively. On contrast, the geographically closest countries, Mexico, Central America, and Canada have the lowest level of naturalization ten years after the initial migration, with $20 \%, 25 \%$, and $27 \%$ on average, respectively. This might reflect that those are also the countries more prone to temporary, circulatory, or illegal immigration.

[Insert Table 2 here]

In terms of labor market outcomes, the immigrants with higher levels of unemployment are those from Dominican Republic and Central America. Unemployment levels peaked in the recent era. Finally, to give some insight of the relative position of immigrants in terms of earnings, the percentile of total individual pre-tax income the previous year to the data collection is calculated with respect to the full U.S. population. The median is reported for each country-cohort-year group. Immigrants from India stand out since they begin with high levels of relative income and increase their relative position through time for all cohorts. Immigrants from Canada, U.K., and Germany also begin relatively high in terms of income, but do not improve their position through time. Immigrants from Philippines begin, on average, below the median, but also greatly increase their relative position through time. On contrast, immigrants from Central America, Mexico, and Dominican Republic begin relatively low and do not greatly improve their position through time.

It is important to mention that the staying population of migrants is not necessarily the same as the group of permanent migrants. In strict terms, the evidence provided here refers to selectivity of long-term migrants while still active on their employment status. There is evidence in the literature that argues that later in life there is a peak of returning migration after retirement (Duleep 1994; Steiner and Velling 1994). 


\subsection{Recent return migration selection}

Finally, an analysis of recent return migration trends uses data from the 2000 Census and the 2010 ACS to investigate if there are any patterns of recent return migration selection in terms of schooling. Figures $7 a$ to $7 e$ present the results for the countries that represent high proportions of immigrant population in the latest years. These graphs illustrate the difference between the 2010 ACS and 2000 Census non-parametric kernel density estimations that use more disaggregated schooling information. The six panels presented in each graph break the analysis by gender, age, naturalization status, and migration spell duration. The sub-samples considered in each of these graphs are: (i) Baseline, which is composed of individuals aged 30 to 55 in 2000 (40 to 65 in 2010) that report arriving to the U.S. between 1995 and 2000; (ii) Females, which is composed of only the female individuals form the Baseline sample; (iii) Older ages, which includes only those individuals aged 40 to 55 in 2000 (50 to 65 in 2010) from the Baseline sample; (iv) Non-Naturalized, which includes those individuals from the Baseline sample that report not having received citizenship; (v) Migrated 1980-89, which includes those individuals aged 40 to 55 in 2000 (50 to 65 in 2010) that report as "first year of entry to live in the U.S." any year between 1980 and 1989; and (vi) Migrated 1990-94, which include those individuals aged 40 to 55 in 2000 (50 to 65 in 2010) that report as "first year of entry to live in the U.S." any year between 1990 and 1994.

\section{[Insert Figures 7a to 7e here]}

A positive (negative) selection of immigrants that stay in the U.S. would result if there is a positive (negative) mass in the differences at higher levels of schooling and a negative (positive) mass at lower levels. In the case of positive selection, the positive mass at higher levels of schooling would mean that a larger proportion of the sample had high levels of school attainment in 2010 than in 2000. Since we assume that the sample observed in 2000 and 2010 are similar by construction, any difference between the schooling distribution is assumed as a result of return migration.

Mixed evidence of positive and negative selectivity in terms of schooling is found for recent migration trends from the countries selected. Mexico, the main source of U.S. immi- 
grants, exhibits a positive selection of migrants that stay in the U.S. High school graduate migrants tend to stay in the U.S. while those with primary or no schooling are more likely to return. This tendency is also observed on the female population, but with lower levels of variation. The older cohort of migrants and those non-naturalized are characterized by a group of migrants with incomplete primary more prone to stay, which leads to a partitioned selection in terms of schooling. Those with higher migration spells show lower variation, but their selection patterns are similar to that of the older cohort, which is the comparable group in terms of age. Central American migrants show a similar pattern to that described of Mexican immigrants, but with lower levels of variation.

Chinese immigrants are the group with the most evident case of negative selection. High school graduates and dropouts are the population that is more likely to stay, while those with a bachelor degree or more leave the country in higher proportions. This tendency is also observed among female, older, and non-naturalized migrants, being the negative selection more pronounced in the latter case. In the case of immigrants with longer migration spells, the selection pattern is different, which suggests that the negative selection is recent. This is consistent with the conclusions from the previous subsection. Indian immigrants have an overall partitioned selection. However, female and older immigrants denote a positive selection. Also the migration spell analysis suggests that the trends have been changing recently. Finally, Philippino immigrants denote a positive selection, with bachelor degree immigrants staying in the U.S. in a higher proportion and high school graduates leaving the country. The pattern is consistent among female and older immigrants, being the selection more pronounced in this last group.

Overall, evidence of positive and negative selection is found for recent immigrant groups. Generally, female and older cohorts behave similarly as the baseline group, with some exceptions. As expected, the non-naturalized population exhibits a worse selection in terms of schooling compared to the baseline group. This shows that education is an important component towards being more successful to gain citizenship. The analysis with migrants with longer migration spells shows that the variability of schooling declines, which might reflect lower mobility as migration spells extend. Also, it suggests that the patterns of 
selection have been recently changing.

\section{Conclusions}

Ten countries were chosen based on their historical and present importance on U.S. migration. The empirical results shown on this paper suggest that there is overwhelming evidence in favor of positive selection of immigrants in terms of schooling, regardless of the source country's level of inequality and returns to schooling compared to the U.S. This positive selectivity has remained through time for most countries and in some cases it has even increased. In contrast, the analysis of return migration suggests that positive selectivity of staying migrants has decreased through time. The cohorts of migrants that arrived before 1980 exhibited positive selection of staying migrants for most of the countries analyzed. However, this positive selection is greatly reduced in later cohorts of migrants that arrived after 1995.

The case of Mexican migration to the U.S. has been the most thoroughly analyzed in the literature given the proportion of immigrants that these population represents. The evidence presented suggests that Mexican migration was positively selected during the 1970's and 1980 's, but through time the positive selectivity disappeared. With respect to recent return migration patterns, the analysis shows slight evidence of positive selection since staying migrants are mostly selected from the upper part of the distribution of migrant's

schooling. Those that stay in the U.S. are mainly selected from the high school graduate population, while those returning are scattered across lower levels of schooling. China, one of the two countries with highest growth of immigrant population in recent decades, denotes a positive selection of immigrant population. However, the recent return migration analysis suggest that immigrants staying in the U.S. are negatively selected for the most recent immigrant wave. Finally, Philippines is a notable case since both incoming migrants and those stay longer in the U.S. are positively selected in terms of schooling, being those with bachelor degrees the most likely immigrants to stay.

Given that immigrants and returning migrants are not a random sample of a country's population, it is crucial to understand and track their patterns of selectivity. This is relevant 
from an economic and policy perspective, both for the source and receiving country. The last decades have witnessed increasing migration flows and it is likely that the upward tendency will continue in the future. As a result, more research is needed to improve our understanding of how migration decisions are taken and what components influence it. 


\section{References}

Akee, R. K. (2007). Who leaves and who returns? Deciphering immigrant self-selection from a developing country. IZA Discussion Paper No. 3268.

Ambrosini, J. W. and G. Peri (2012). The determinants and the selection of Mexico-US migrants. The World Economy 35(2), 111-151.

Barrett, A. and J. Goggin (2010). Returning to the question of a wage premium for returning migrants. National Institute Economic Review 213(1), R43-R51.

Barrett, A. and P. J. O'Connell (2001). Is there a wage premium for returning Irish migrants? The Economic and Social Review 32(1), 1-21.

Barro, R. and J.-W. Lee (2010). A new data set of educational attainment in the world. National Bureau of Economic Research Working Paper No. 15902.

Borjas, G. (1987). Self-selection and the earnings of immigrants. American Economic Review $77(4), 531-553$.

Borjas, G. (1991). Immigration and self-selection. In J. Abowd and R. Freeman (Eds.), Immigration, Trade, and the Labor Market, Chicago, IL, pp. 29-76. University of Chicago Press.

Borjas, G. (1999). The economic analysis of immigration. In O. C. Ashenfelter and D. Card (Eds.), Handbook of Labor Economics, Volume 3, pp. 1697-1760. Elsevier.

Borjas, G. J. (1989). Immigrant and emigrant earnings: A longitudinal study. Economic Inquiry 27(1), 21-37.

Borjas, G. J. and B. Bratsberg (1996). Who leaves? The outmigration of the foreign-born. Review of Economics and Statistics 78(1), 165-176.

Borjas, G. J. and R. Friedberg (2009). Recent trends in the earnings of new immigrants to the United States. National Bureau of Economic Research Working Paper No. 15406.

Carliner, G. (1980). Wages, earnings and hours of first, second and third generation American males. Economic Inquiry 18(1), 87-102. 
Chiquiar, D. and G. Hanson (2005). International migration, self-selection, and the distribution of wages: Evidence from Mexico and the United States. Journal of Political Economy 113(2), 239-281.

Chiswick, B. R. (1978). The effect of americanization on the earnings of foreign-born men. Journal of Political Economy 86(5), 897-921.

Co, C. Y., I. N. Gang, and M.-S. Yun (2000). Returns to returning. Journal of Population Economics 13(1), 57-79.

Coulon, A. and M. Piracha (2005). Self-selection and the performance of return migrants: the source country perspective. Journal of Population Economics 18(4), 779-807.

Department of Homeland Security (Last consulted: April 16, 2012). Yearbook of immigration statistics: 2011. http://www.dhs.gov/files/statistics/publications/LPR11. shtm.

Duleep, H. (1994). Social security and the emigration of immigrants. Social Security Bulletin 57(1), 37-52.

Dustmann, C., I. Fadlon, and Y. Weiss (2011). Return migration, human capital accumulation and the brain drain. Journal of Development Economics 95(1), 58-67.

Feliciano, C. (2005). Educational selectivity in U.S. immigration: How do immigrants compare to those left behind? Demography 42(1), 131-152.

Fernández-Huertas Moraga, J. (2011). New evidence on emigrant selection. The Review of Economics and Statistics 93(1), 72-96.

Hanson, G. H. (2007). Emigration, labor supply, and earnings in Mexico. In Mexican Immigration to the United States, NBER Chapters, pp. 289-328. National Bureau of Economic Research.

Iara, A. (2006). Skill diffusion by temporary migration? Returns to Western European working experience in the EU accession countries. Development Working Papers 210, Centro Studi Luca dÁgliano, University of Milano. 
Ibarraran, P. and D. Lubotsky (2007). Mexican Immigration and Self-Selection: New Evidence from the 2000 Mexican Census, pp. 159-192. University of Chicago Press.

Jasso, G. and M. R. Rosenzweig (1988). How well do U.S. immigrants do? Vintage effects, emigration selectivity, and occupational mobility. Research in Human Capital and Development 6, 229-253.

Kaestner, R. and O. Malamud (2010). Self-selection and international migration: New evidence from Mexico. NBER Working Papers 15765, National Bureau of Economic Research, Inc.

Koser, K. and F. Laczko (Eds.) (2010). World Migration Report 2010. The future of migration: Building capacities for change, Geneva, Switzerland. IOM: International Organization for Migration.

Orrenius, P. M. and M. Zavodny (2005). Self-selection among undocumented immigrants from Mexico. Journal of Development Economics 78(1), 215-240.

Passel, J. and D. Cohn (2010). Unauthorized immigrant population: National and State trends, 2010. Technical report, Pew Hispanic Center, Washington D.C.

Psacharopoulos, G. and H. Patrinos (2002). Returns to investment in education. a further update. World Bank Policy Research Working Paper No. 2881.

Reinhold, S. and K. Thom (2009). Temporary migration, skill upgrading, and legal status. evidence from Mexican migrants. MEA Discussion Paper No. 182-09.

Roy, A. (1951). Some thoughts on the distribution of earnings. Oxford Economic Papers 3(2), 135-146.

Ruggles, S., J. T. Alexander, K. Genadek, R. Goeken, M. B. Schroeder, and M. Sobek (2010). Integrated Public Use Microdata Series: Version 5.0. Minneapolis: University of Minnesota.

Silverman, B. W. (1986). Density estimation for statistics and data analysis. London: Chapman and Hall. 
Steiner, V. and J. Velling (1994). Re-migration behavior and expected duration of stay of guest workers in Germany. In G. Steinmann and R. Ulrich (Eds.), The Economic Consequences of Immigration to Germany, Germany, pp. 101-119. Physica-Verlag.

United Nations (2008). UNU-WIDER. World income inequality database: User guide and data sources. Technical report, World Institute for Development Economics Research, Washington D.C. 
Table 1: Top source countries of immigration to the United States

\begin{tabular}{|c|c|c|c|c|c|c|}
\hline Rank & 1970 & Pop $(, 000)$ & $\%$ & 1980 & Pop $(, 000)$ & $\%$ \\
\hline 1 & Italy & 1,009 & $10.5 \%$ & Mexico & 2,199 & $15.6 \%$ \\
\hline 2 & Germany & 833 & $8.7 \%$ & Germany & 849 & $6.0 \%$ \\
\hline 3 & Canada & 812 & $8.4 \%$ & Canada & 843 & $6.0 \%$ \\
\hline 4 & Mexico & 760 & $7.9 \%$ & Italy & 832 & $5.9 \%$ \\
\hline 5 & U.K. & 686 & $7.1 \%$ & U.K. & 669 & $4.8 \%$ \\
\hline 6 & Poland & 548 & $5.7 \%$ & Cuba & 608 & $4.3 \%$ \\
\hline 7 & U.S.S.R. & 463 & $4.8 \%$ & Philippines & 501 & $3.6 \%$ \\
\hline 8 & Cuba & 439 & $4.6 \%$ & Poland & 418 & $3.0 \%$ \\
\hline 9 & Ireland & 251 & $2.6 \%$ & U.S.S.R. & 406 & $2.9 \%$ \\
\hline 10 & Austria & 214 & $2.2 \%$ & Korea & 290 & $2.1 \%$ \\
\hline Rank & 1990 & Pop $(, 000)$ & $\%$ & 2000 & Pop $(, 000)$ & $\%$ \\
\hline 1 & Mexico & 4,298 & $21.7 \%$ & Mexico & 9,177 & $29.5 \%$ \\
\hline 2 & Philippines & 913 & $4.6 \%$ & Philippines & 1,369 & $4.4 \%$ \\
\hline 3 & Canada & 745 & $3.8 \%$ & India & 1,023 & $3.3 \%$ \\
\hline 4 & Cuba & 737 & $3.7 \%$ & China & 989 & $3.2 \%$ \\
\hline 5 & Germany & 712 & $3.6 \%$ & Vietnam & 988 & $3.2 \%$ \\
\hline 6 & U.K. & 640 & $3.2 \%$ & Cuba & 873 & $2.8 \%$ \\
\hline 7 & Italy & 581 & $2.9 \%$ & Korea & 864 & $2.8 \%$ \\
\hline 8 & Korea & 568 & $2.9 \%$ & Canada & 821 & $2.6 \%$ \\
\hline 9 & Vietnam & 543 & $2.7 \%$ & El Salvador & 817 & $2.6 \%$ \\
\hline 10 & China & 530 & $2.7 \%$ & Germany & 707 & $2.3 \%$ \\
\hline Rank & 2010 & Pop $(, 000)$ & $\%$ & & & \\
\hline 1 & Mexico & 11,711 & $29.3 \%$ & & & \\
\hline 2 & India & 1,780 & $4.5 \%$ & & & \\
\hline 3 & Philippines & 1,778 & $4.4 \%$ & & & \\
\hline 4 & China & 1,608 & $4.0 \%$ & & & \\
\hline 5 & Vietnam & 1,241 & $3.1 \%$ & & & \\
\hline 6 & El Salvador & 1,214 & $3.0 \%$ & & & \\
\hline 7 & Cuba & 1,105 & $2.8 \%$ & & & \\
\hline 8 & Korea & 1,100 & $2.8 \%$ & & & \\
\hline 9 & Dom. Rep. & 879 & $2.2 \%$ & & & \\
\hline 10 & Guatemala & 831 & $2.1 \%$ & & & \\
\hline
\end{tabular}

Source: U.S. 1970, 1980, 1990, and 2000 Census and 2010 American Community Survey 
Table 2: Descriptive statistics for each country by year and cohort

\begin{tabular}{|c|c|c|c|c|c|c|c|c|c|c|c|}
\hline \multirow[b]{2}{*}{ Cohort } & \multirow[b]{2}{*}{ Year } & \multicolumn{10}{|c|}{ Country } \\
\hline & & CAM & CAN & $\mathrm{CHI}$ & D.R. & ENG & GER & IND & ITA & MEX & $\mathrm{PHI}$ \\
\hline \multicolumn{12}{|c|}{ a. Proportion of male immigrants } \\
\hline 1 & 1970 & 0.48 & 0.77 & 0.72 & 0.53 & 0.77 & 0.68 & 0.82 & 0.64 & 0.68 & 0.56 \\
\hline 1 & 1980 & 0.38 & 0.58 & 0.58 & 0.51 & 0.60 & 0.43 & 0.79 & 0.66 & 0.63 & 0.47 \\
\hline 1 & 1990 & 0.45 & 0.55 & 0.55 & 0.61 & 0.55 & 0.39 & 0.75 & 0.67 & 0.61 & 0.45 \\
\hline 2 & 1980 & 0.53 & 0.64 & 0.60 & 0.57 & 0.70 & 0.64 & 0.69 & 0.74 & 0.74 & 0.46 \\
\hline 2 & 1990 & 0.50 & 0.50 & 0.57 & 0.60 & 0.59 & 0.35 & 0.64 & 0.65 & 0.66 & 0.43 \\
\hline 2 & 2000 & 0.47 & 0.50 & 0.56 & 0.60 & 0.60 & 0.38 & 0.61 & 0.59 & 0.63 & 0.42 \\
\hline 3 & 1990 & 0.59 & 0.61 & 0.57 & 0.54 & 0.71 & 0.59 & 0.70 & 0.71 & 0.73 & 0.42 \\
\hline 3 & 2000 & 0.52 & 0.56 & 0.55 & 0.55 & 0.63 & 0.44 & 0.66 & 0.62 & 0.64 & 0.41 \\
\hline 3 & 2010 & 0.53 & 0.40 & 0.54 & 0.54 & 0.50 & 0.40 & 0.62 & 0.69 & 0.66 & 0.36 \\
\hline 4 & 2000 & 0.65 & 0.62 & 0.56 & 0.50 & 0.71 & 0.63 & 0.74 & 0.63 & 0.71 & 0.44 \\
\hline 4 & 2010 & 0.58 & 0.56 & 0.53 & 0.48 & 0.67 & 0.48 & 0.66 & 0.68 & 0.62 & 0.41 \\
\hline \multicolumn{12}{|c|}{ b. Proportion of naturalized immigrants } \\
\hline 1 & 1970 & 0.15 & 0.06 & 0.16 & 0.30 & 0.01 & 0.12 & 0.06 & 0.09 & 0.25 & 0.07 \\
\hline 1 & 1980 & 0.36 & 0.27 & 0.66 & 0.28 & 0.39 & 0.44 & 0.56 & 0.51 & 0.21 & 0.75 \\
\hline 1 & 1990 & 0.53 & 0.34 & 0.84 & 0.47 & 0.46 & 0.54 & 0.73 & 0.62 & 0.29 & 0.90 \\
\hline 2 & 1980 & 0.07 & 0.05 & 0.06 & 0.14 & 0.01 & 0.11 & 0.06 & 0.13 & 0.12 & 0.09 \\
\hline 2 & 1990 & 0.27 & 0.18 & 0.72 & 0.24 & 0.20 & 0.34 & 0.56 & 0.39 & 0.24 & 0.78 \\
\hline 2 & 2000 & 0.57 & 0.44 & 0.86 & 0.49 & 0.42 & 0.47 & 0.81 & 0.58 & 0.36 & 0.90 \\
\hline 3 & 1990 & 0.06 & 0.08 & 0.05 & 0.12 & 0.06 & 0.12 & 0.05 & 0.12 & 0.11 & 0.12 \\
\hline 3 & 2000 & 0.22 & 0.30 & 0.53 & 0.36 & 0.29 & 0.43 & 0.54 & 0.47 & 0.24 & 0.66 \\
\hline 3 & 2010 & 0.37 & 0.45 & 0.84 & 0.60 & 0.61 & 0.43 & 0.84 & 0.62 & 0.34 & 0.85 \\
\hline 4 & 2000 & 0.06 & 0.10 & 0.04 & 0.08 & 0.12 & 0.27 & 0.04 & 0.13 & 0.07 & 0.12 \\
\hline 4 & 2010 & 0.19 & 0.32 & 0.42 & 0.40 & 0.34 & 0.31 & 0.57 & 0.38 & 0.15 & 0.65 \\
\hline
\end{tabular}

Source: U.S. 1970, 1980, 1990, and 2000 Census and 2010 American Community Survey 
Table 2: Descriptive statistics for each country by year and cohort (cont.)

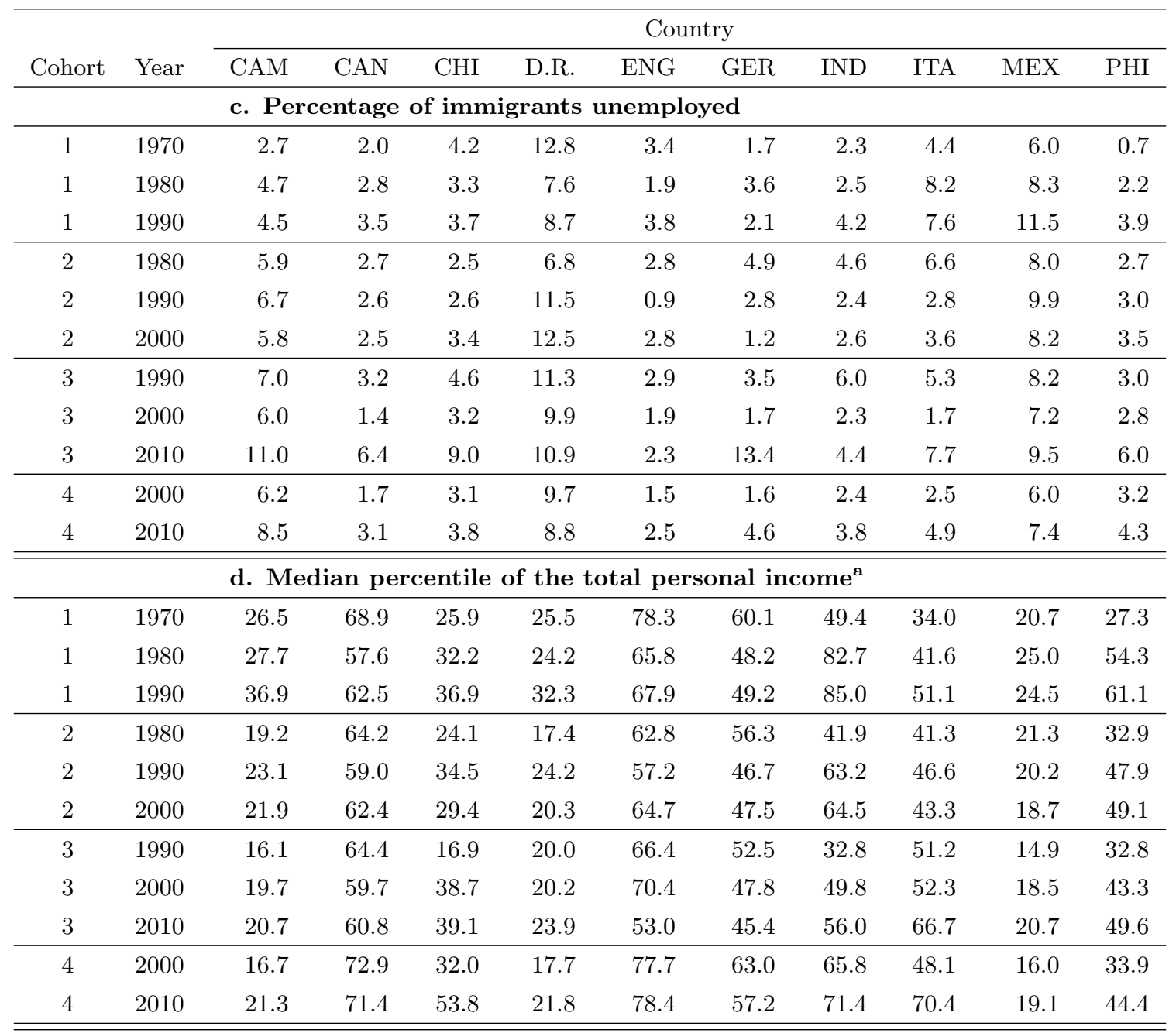

Source: U.S. 1970, 1980, 1990, and 2000 Census and 2010 American Community Survey

a Median percentile income is calculated with respect to the full U.S. employed population over 15 years old 


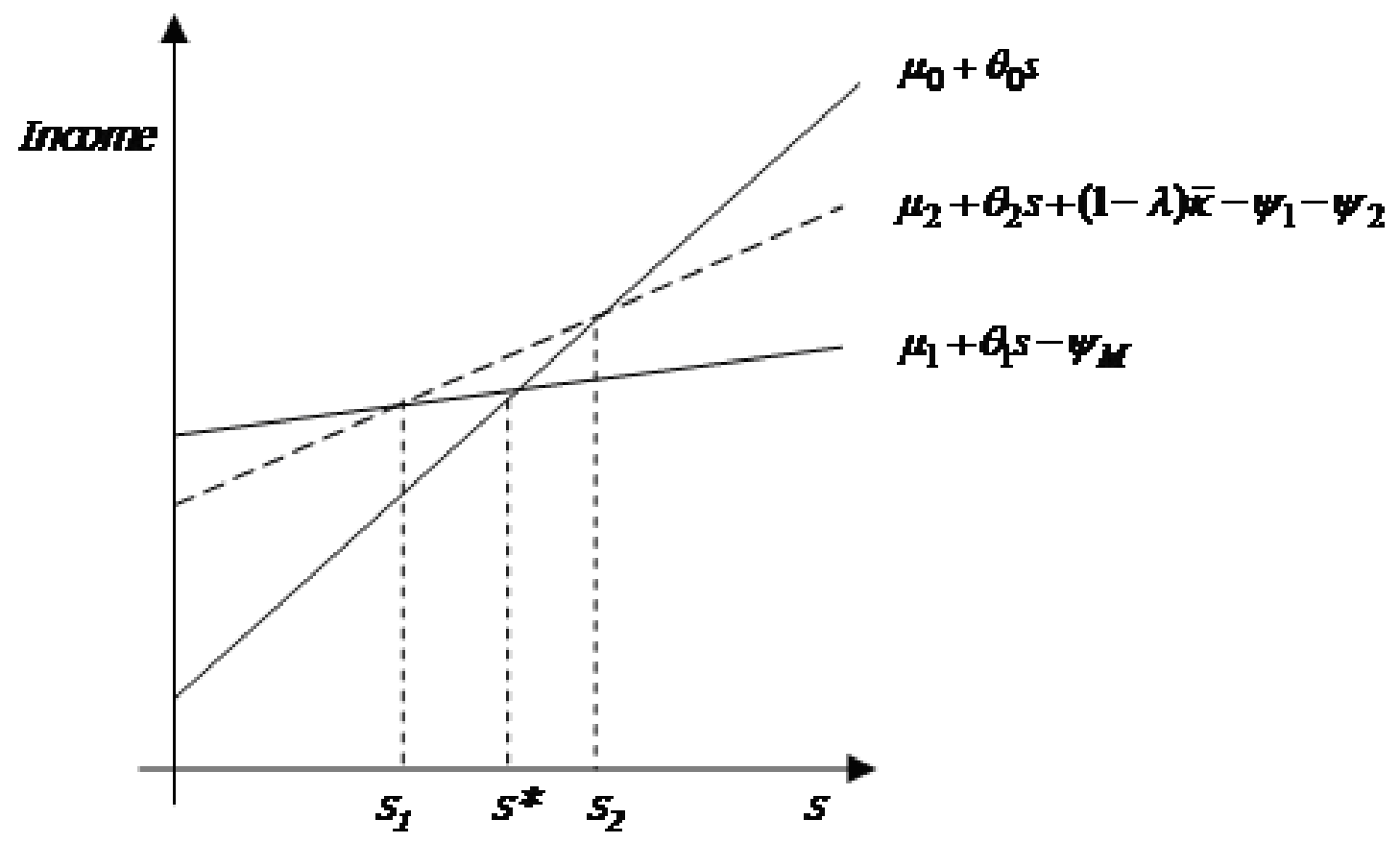

Figure 1: Negative selection with temporary migration

This figure assumes that $\theta_{0}>\theta_{1}, \mu_{1}>\mu_{0}, \psi_{M}\left(s_{i}\right)=\psi_{1}, \psi_{R}\left(s_{i}\right)=\psi_{2}, \kappa\left(s_{i}\right)=\bar{\kappa}$.

In the temporary migration option (dotted line), $\mu_{2}=\lambda \mu_{1}+(1-\lambda) \mu_{0}$, and $\theta_{2}=\lambda \theta_{1}+(1-\lambda) \theta_{0}$.

The optimal choice for individuals with $s_{i}<s_{1}$ is to migrate permanently, for individuals with $s_{1}<s_{i}<s_{2}$ to migrate temporally, and for individuals with $s_{i}>s_{2}$ is to remain in the source country. 


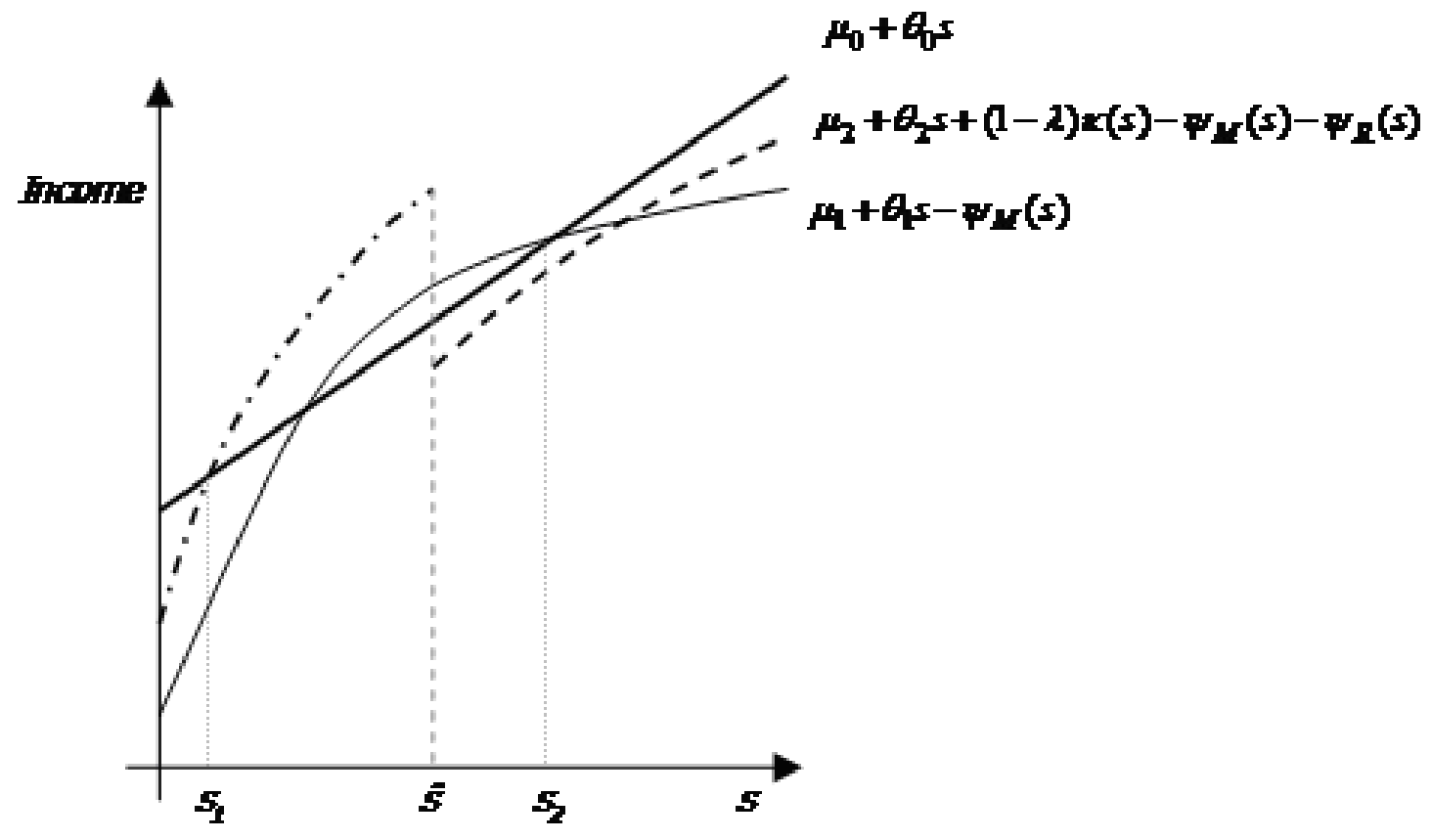

Figure 2: Mixed migration selection with temporary migration

This figure assumes that $\theta_{0}>\theta_{1}$ and $\mu_{0}>\mu_{1}$.

In the temporary migration option (dotted line), $\mu_{2}=\lambda \mu_{1}+(1-\lambda) \mu_{0}$, and $\theta_{2}=\lambda \theta_{1}+(1-\lambda) \theta_{0}$

The optimal choice for individuals with $s_{i}<s_{1}$ is not to migrate, for individuals with $s_{1}<s_{i}<\hat{s}$ to migrate temporally, for individuals with $\hat{s}<s_{i}<s_{2}$ to migrate permanently, and for individuals with $s_{i}>s_{2}$ is to remain in the source country 


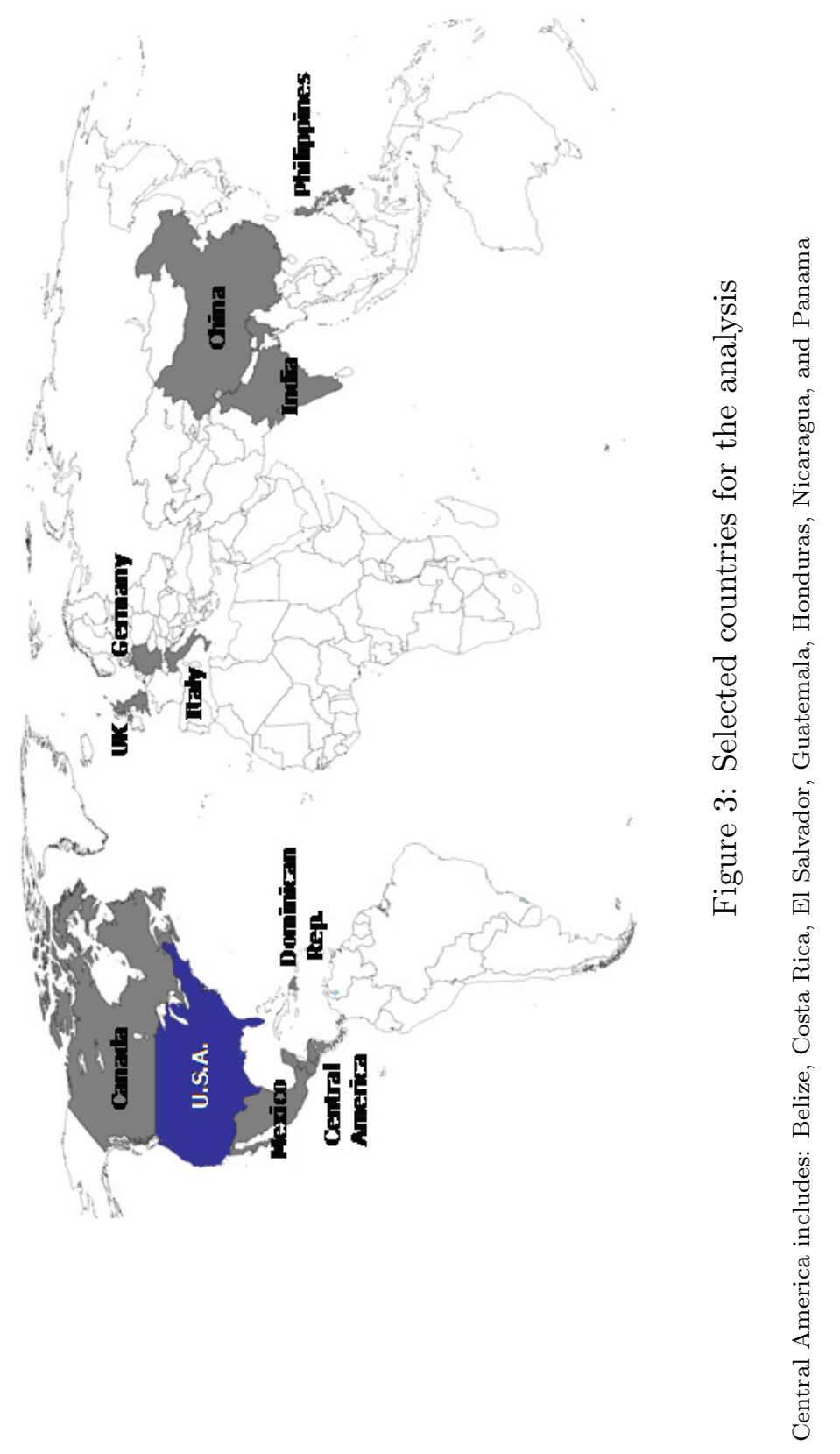




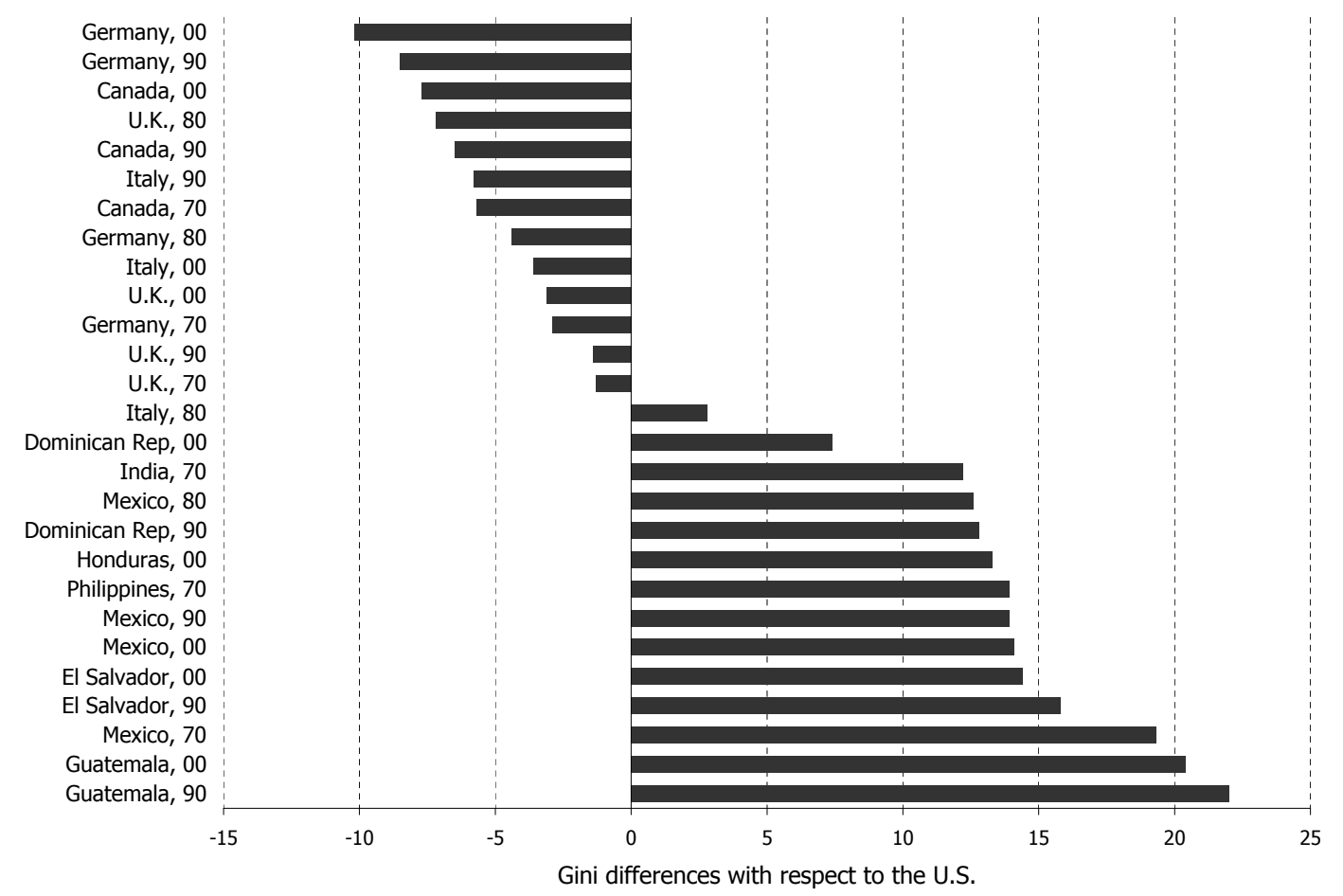

Figure 4: GINI index differences of source countries with respect to the United States

GINI index is measured between 0 and 100 .

A positive (negative) value indicates that the source country is more (less) unequal than the United States. According to the theoretical framework described in Section 2, this should help predict the type of selectivity of immigrants and returning migrants.

Source of GINI indexes: UNU-WIDER dataset (United Nations 2008). 


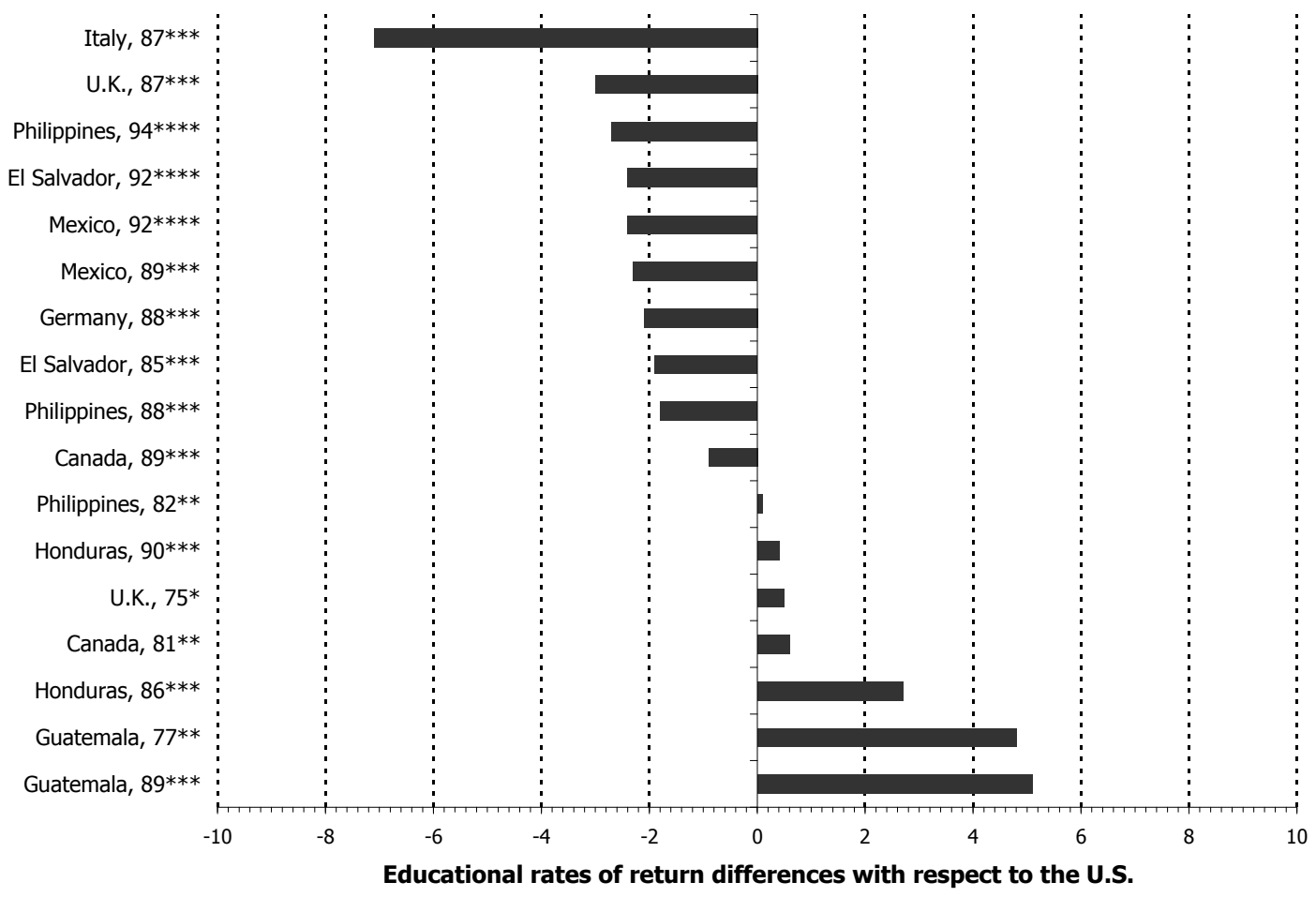

Figure 5: Educational rates of return differences of source countries with respect to the United States

Differences are in percentage points.

A positive (negative) value indicates that the source country has higher (lower) rates of return to years of schooling than the United States.

Source of rates of return to schooling: Psacharopoulos and Patrinos (2002). 


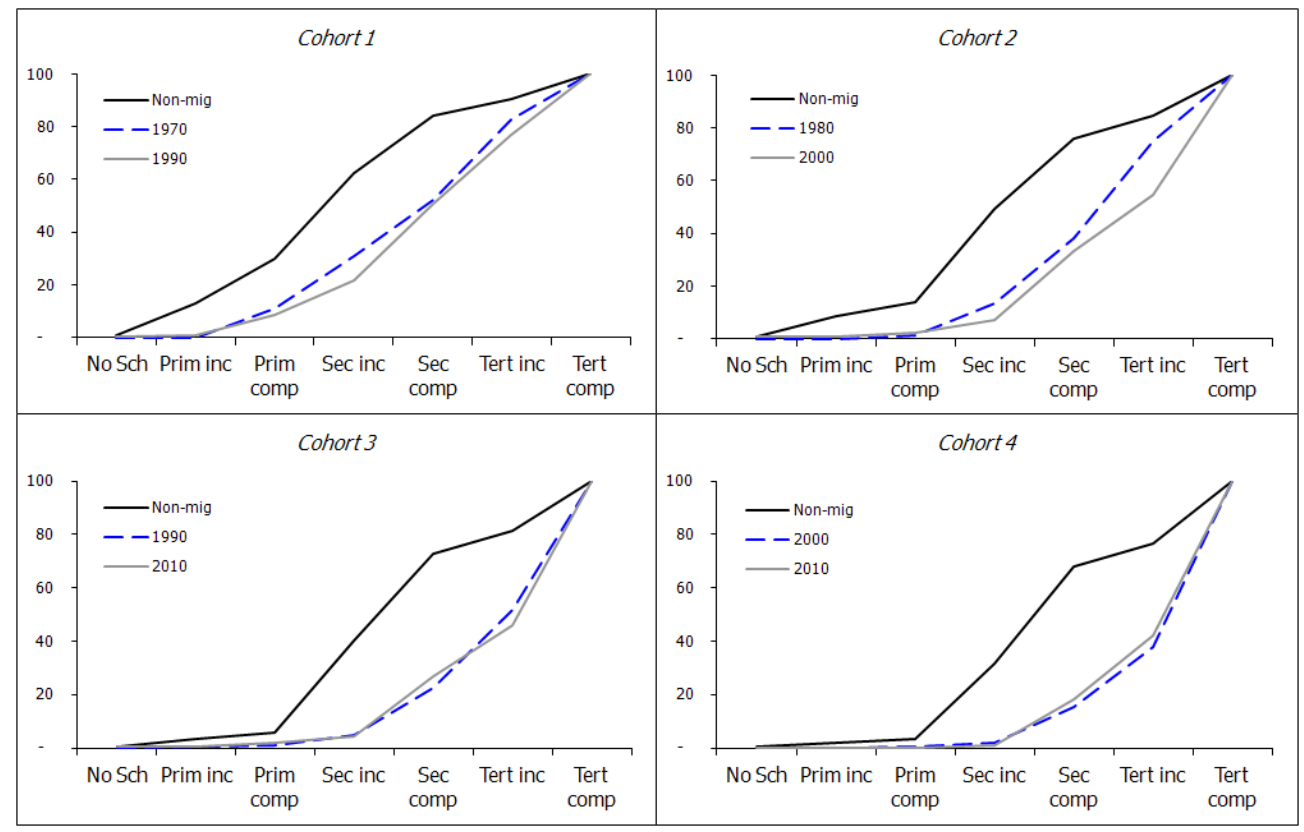

Figure 6a: Immigrant and return migration. CANADA

Cohort 1: Immigrants arrived 1965-1970. Aged 30-45 in 1970 (50-65 in 1990)

Cohort 2: Immigrants arrived 1975-1980. Aged 30-45 in 1980 (50-65 in 2000)

Cohort 3: Immigrants arrived 1985-1990. Aged 30-45 in 1990 (50-65 in 2010)

Cohort 4: Immigrants arrived 1995-2000. Aged 30-45 in 2000 (40-55 in 2010) 

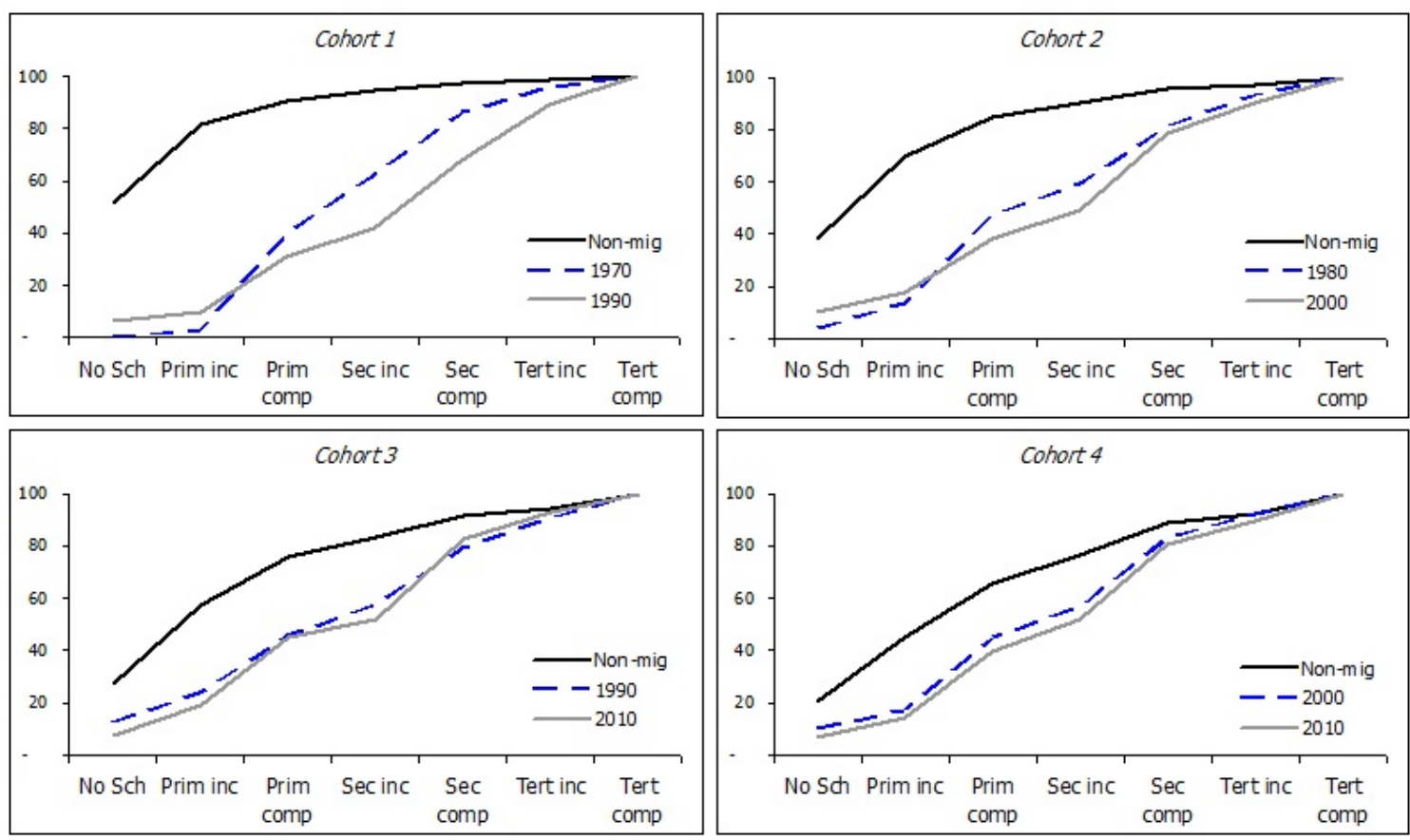

Figure 6b: Immigrant and return migration. CENTRAL AMERICA

Central America includes: Belize, Costa Rica, El Salvador, Guatemala, Honduras, Nicaragua, and Panama.

Cohort 1: Immigrants arrived 1965-1970. Aged 30-45 in 1970 (50-65 in 1990)

Cohort 2: Immigrants arrived 1975-1980. Aged 30-45 in 1980 (50-65 in 2000)

Cohort 3: Immigrants arrived 1985-1990. Aged 30-45 in 1990 (50-65 in 2010)

Cohort 4: Immigrants arrived 1995-2000. Aged 30-45 in 2000 (40-55 in 2010) 

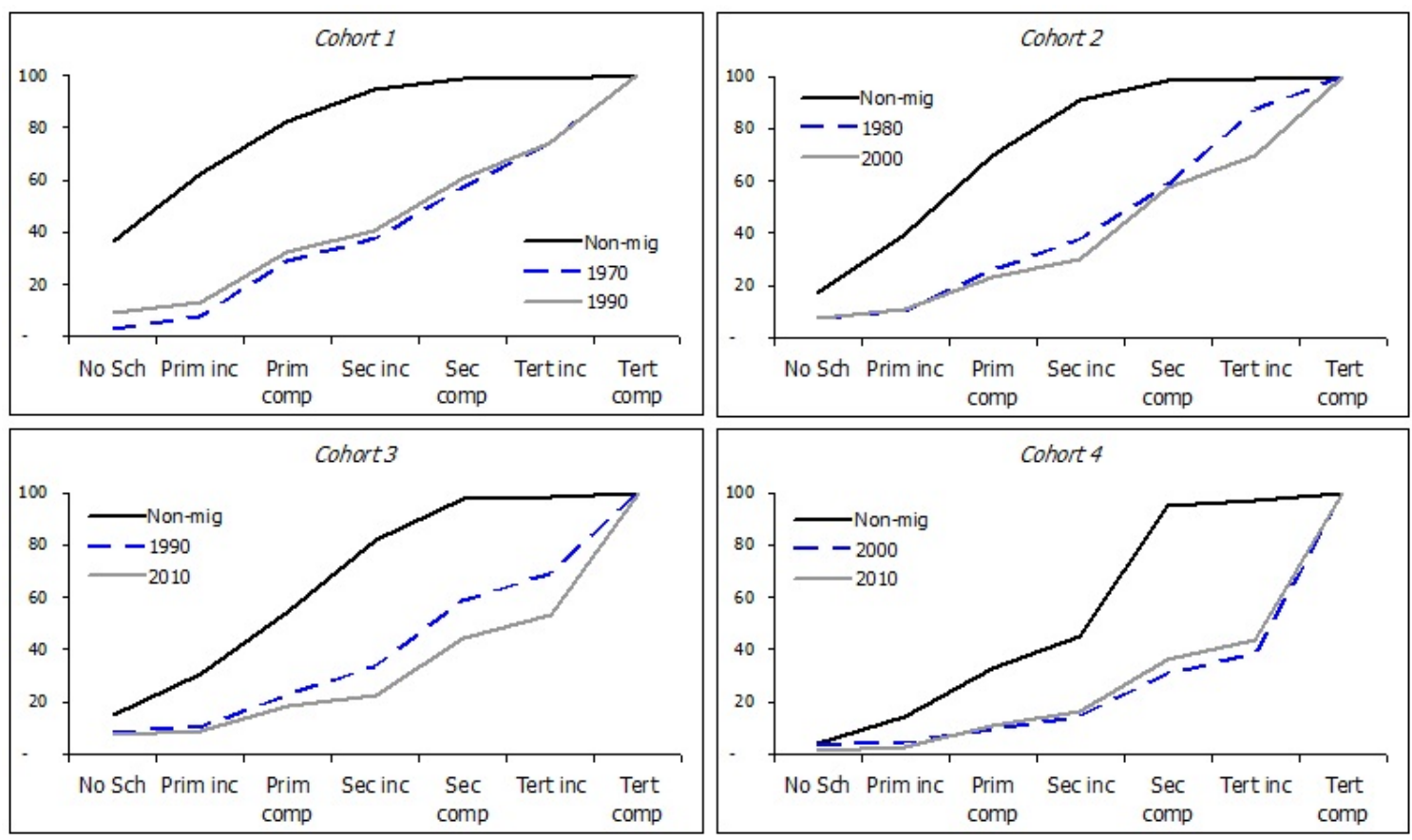

Figure 6c: Immigrant and return migration. CHINA

Cohort 1: Immigrants arrived 1965-1970. Aged 30-45 in 1970 (50-65 in 1990)

Cohort 2: Immigrants arrived 1975-1980. Aged 30-45 in 1980 (50-65 in 2000)

Cohort 3: Immigrants arrived 1985-1990. Aged 30-45 in 1990 (50-65 in 2010)

Cohort 4: Immigrants arrived 1995-2000. Aged 30-45 in 2000 (40-55 in 2010) 

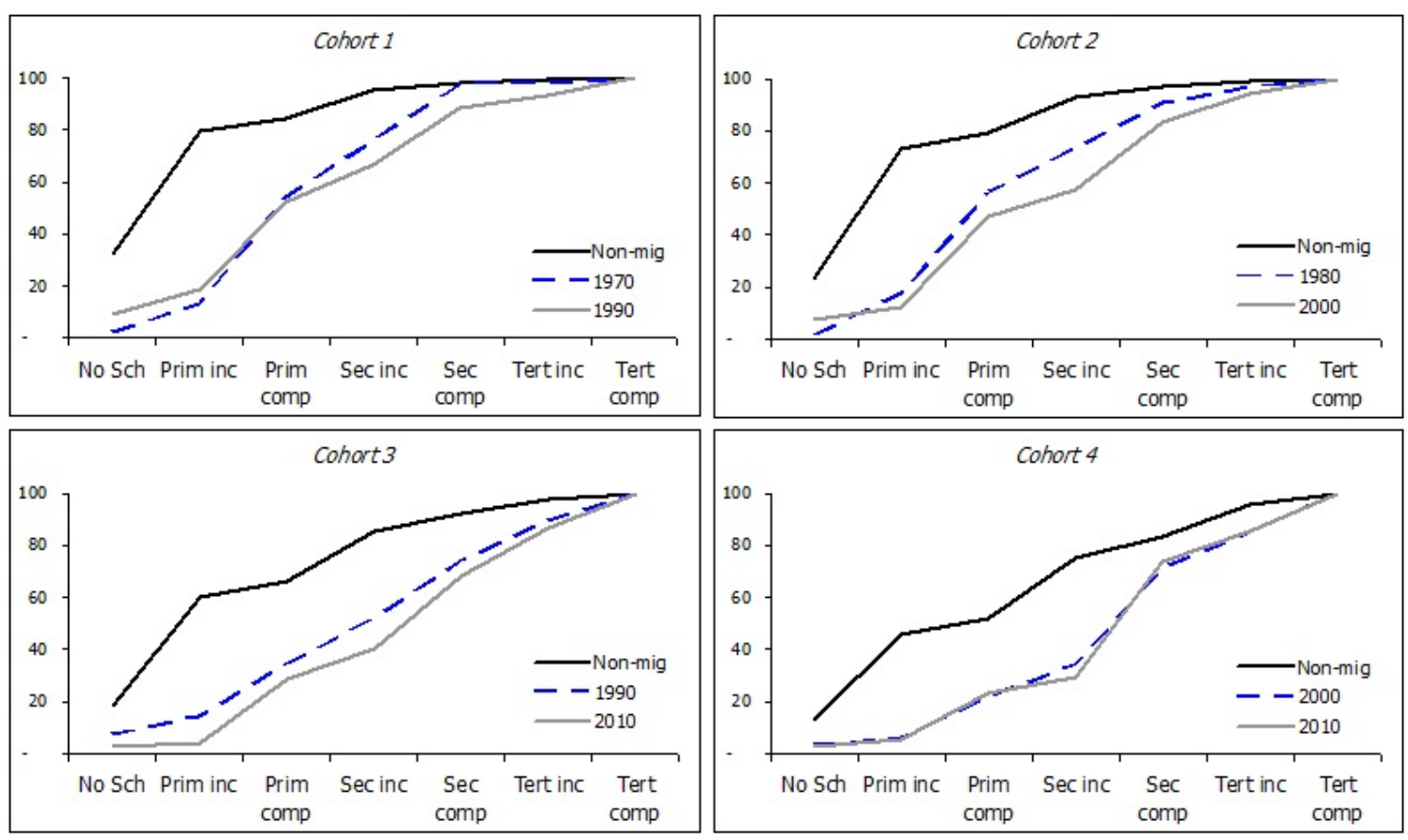

Figure 6d: Immigrant and return migration. DOMINICAN REPUBLIC

Cohort 1: Immigrants arrived 1965-1970. Aged 30-45 in 1970 (50-65 in 1990)

Cohort 2: Immigrants arrived 1975-1980. Aged 30-45 in 1980 (50-65 in 2000)

Cohort 3: Immigrants arrived 1985-1990. Aged 30-45 in 1990 (50-65 in 2010)

Cohort 4: Immigrants arrived 1995-2000. Aged 30-45 in 2000 (40-55 in 2010) 

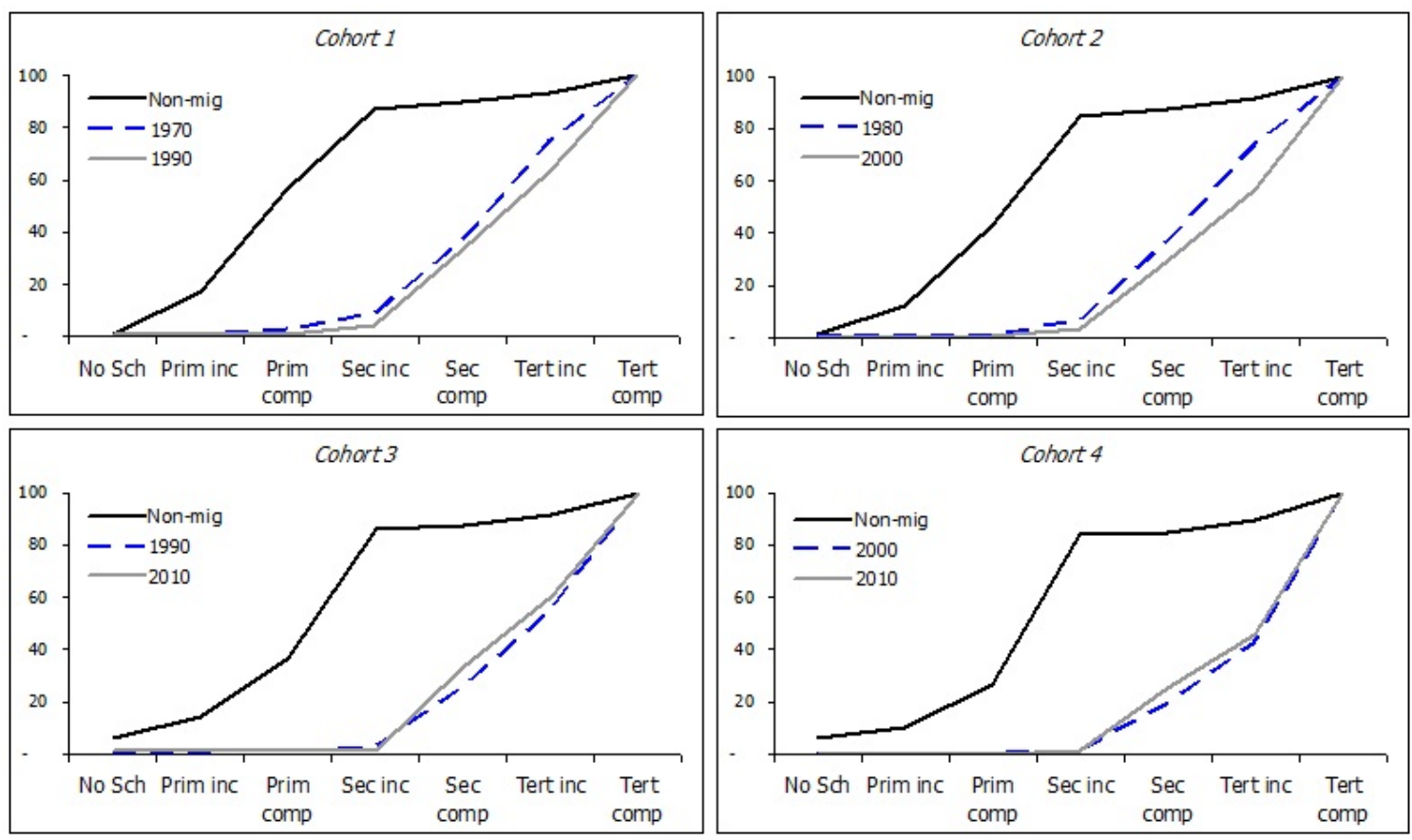

Figure 6e: Immigrant and return migration. ENGLAND

Cohort 1: Immigrants arrived 1965-1970. Aged 30-45 in 1970 (50-65 in 1990)

Cohort 2: Immigrants arrived 1975-1980. Aged 30-45 in 1980 (50-65 in 2000)

Cohort 3: Immigrants arrived 1985-1990. Aged 30-45 in 1990 (50-65 in 2010)

Cohort 4: Immigrants arrived 1995-2000. Aged 30-45 in 2000 (40-55 in 2010) 

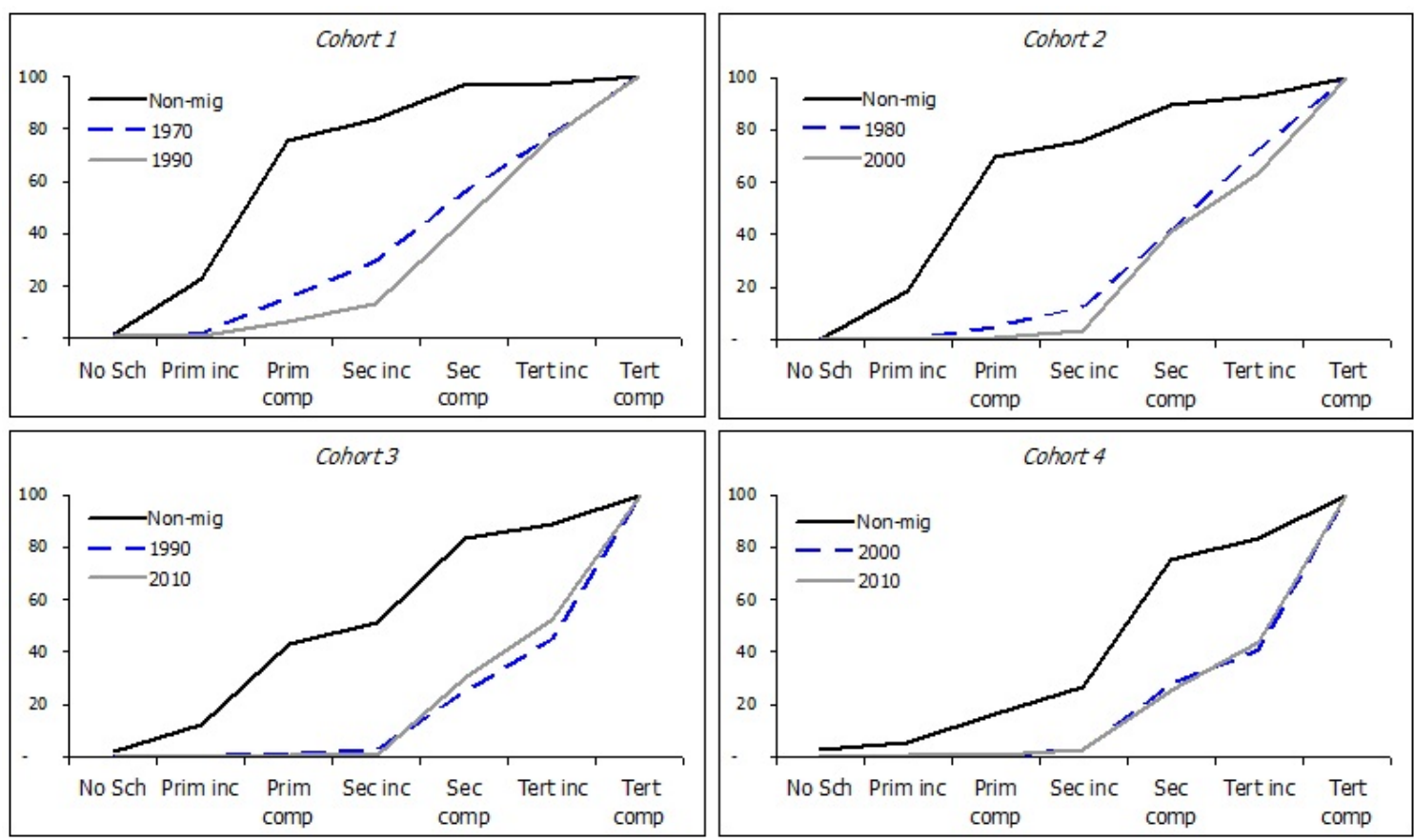

Figure 6f: Immigrant and return migration. GERMANY

Includes Eastern and Western Germany previous to 1990.

Cohort 1: Immigrants arrived 1965-1970. Aged 30-45 in 1970 (50-65 in 1990)

Cohort 2: Immigrants arrived 1975-1980. Aged 30-45 in 1980 (50-65 in 2000)

Cohort 3: Immigrants arrived 1985-1990. Aged 30-45 in 1990 (50-65 in 2010)

Cohort 4: Immigrants arrived 1995-2000. Aged 30-45 in 2000 (40-55 in 2010) 

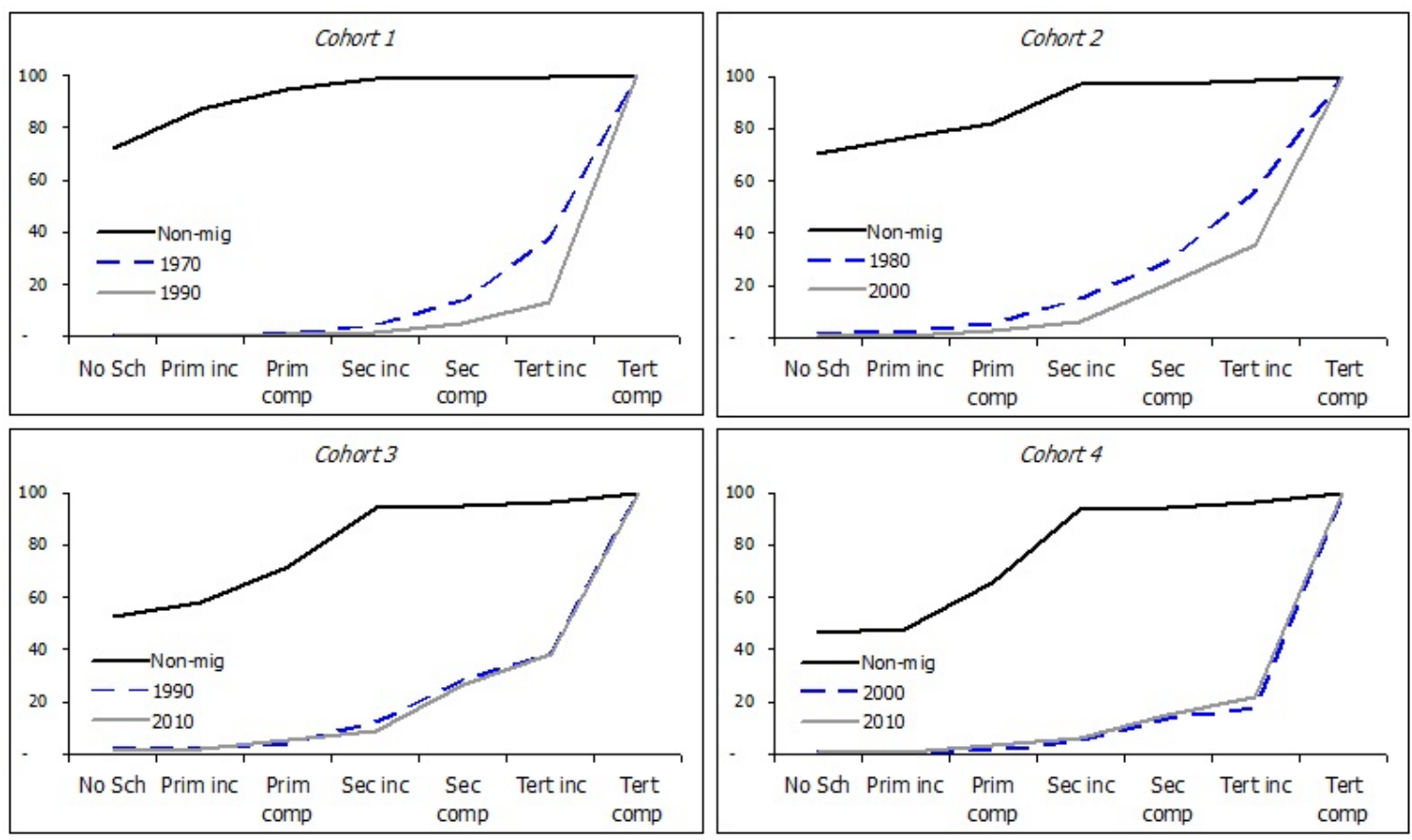

Figure 6g: Immigrant and return migration. INDIA

Cohort 1: Immigrants arrived 1965-1970. Aged 30-45 in 1970 (50-65 in 1990)

Cohort 2: Immigrants arrived 1975-1980. Aged 30-45 in 1980 (50-65 in 2000)

Cohort 3: Immigrants arrived 1985-1990. Aged 30-45 in 1990 (50-65 in 2010)

Cohort 4: Immigrants arrived 1995-2000. Aged 30-45 in 2000 (40-55 in 2010) 

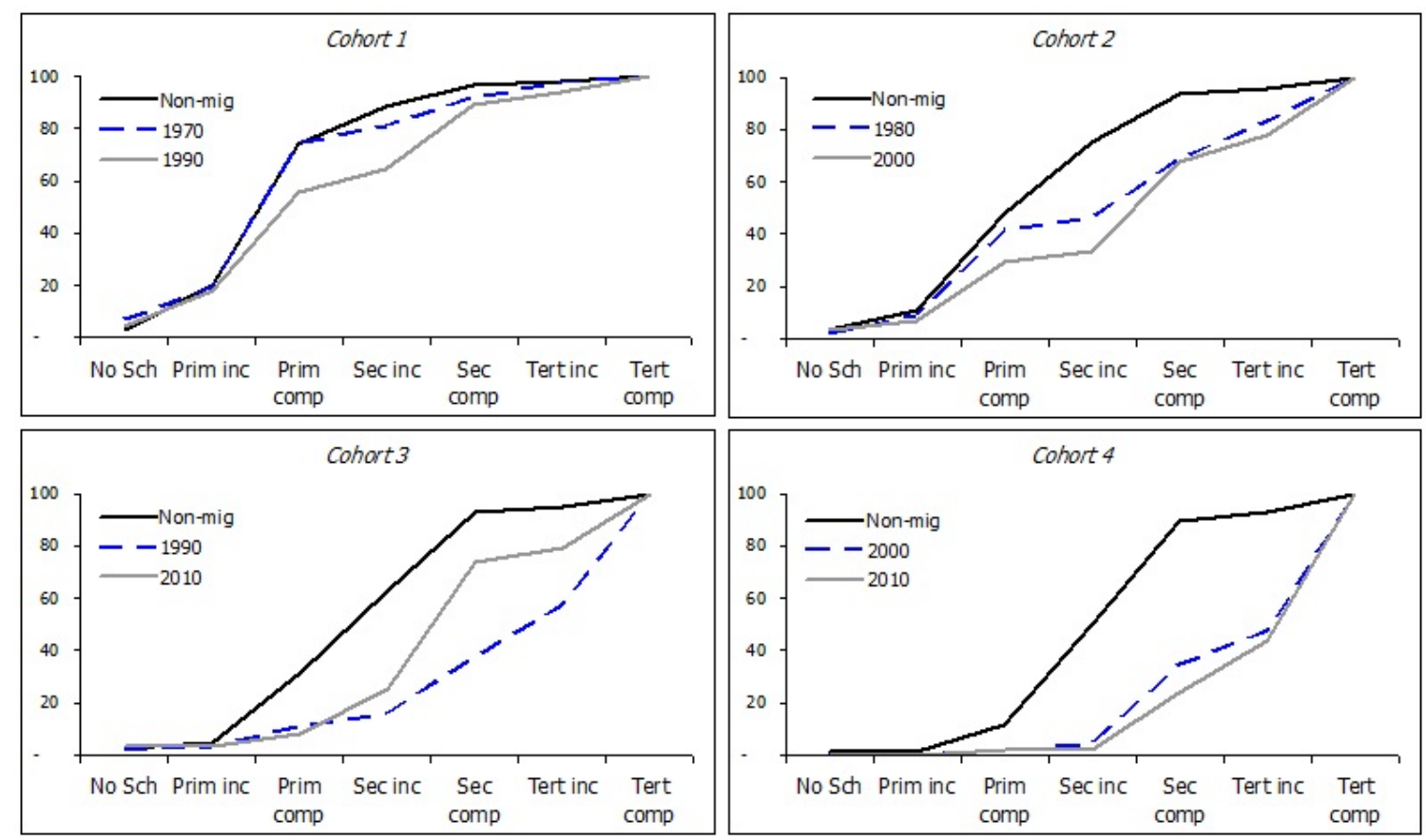

Figure 6h: Immigrant and return migration. ITALY

Cohort 1: Immigrants arrived 1965-1970. Aged 30-45 in 1970 (50-65 in 1990)

Cohort 2: Immigrants arrived 1975-1980. Aged 30-45 in 1980 (50-65 in 2000)

Cohort 3: Immigrants arrived 1985-1990. Aged 30-45 in 1990 (50-65 in 2010)

Cohort 4: Immigrants arrived 1995-2000. Aged 30-45 in 2000 (40-55 in 2010) 

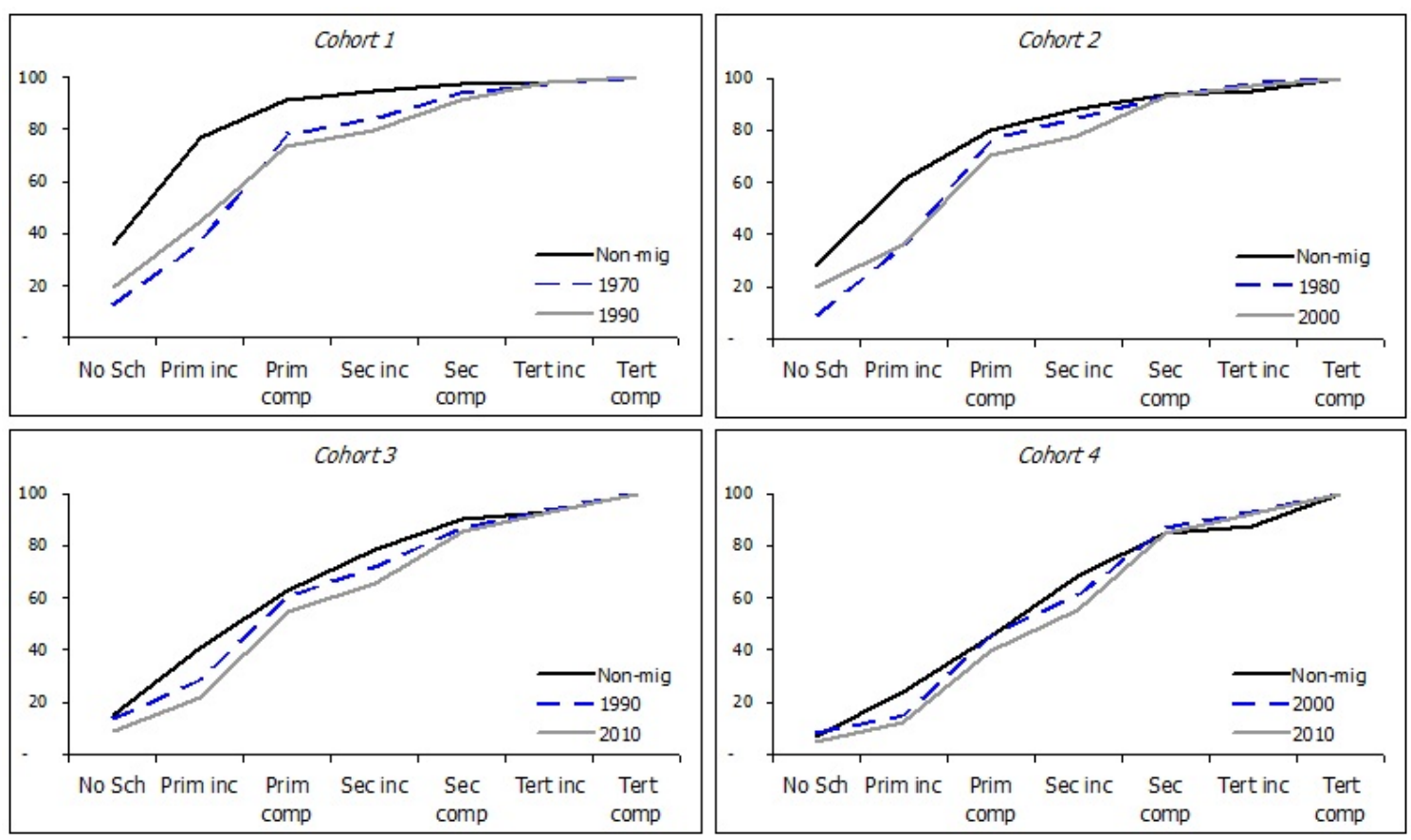

Figure 6i: Immigrant and return migration. MEXICO

Cohort 1: Immigrants arrived 1965-1970. Aged 30-45 in 1970 (50-65 in 1990)

Cohort 2: Immigrants arrived 1975-1980. Aged 30-45 in 1980 (50-65 in 2000)

Cohort 3: Immigrants arrived 1985-1990. Aged 30-45 in 1990 (50-65 in 2010)

Cohort 4: Immigrants arrived 1995-2000. Aged 30-45 in 2000 (40-55 in 2010) 

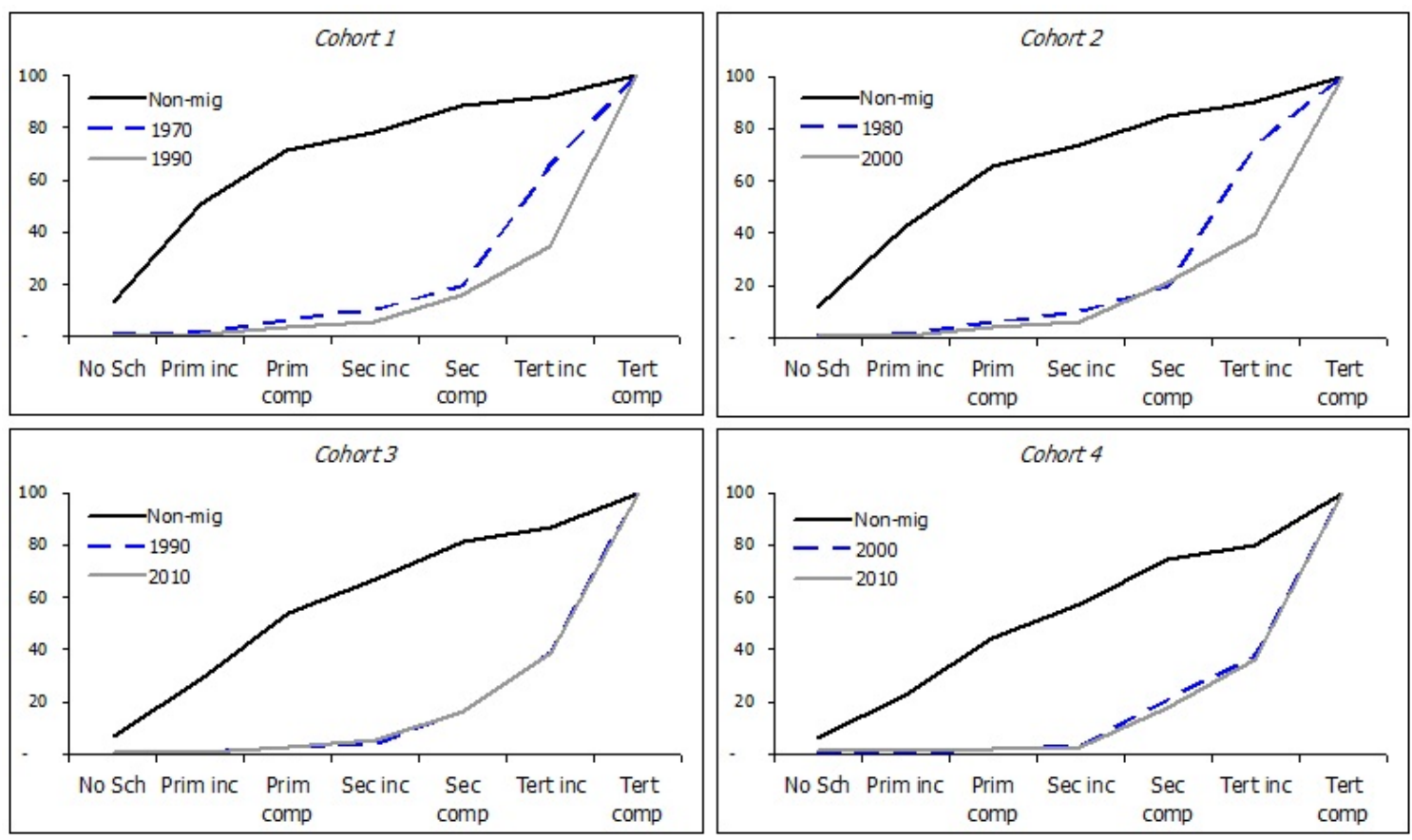

Figure 6j: Immigrant and return migration. PHILIPPINES

Cohort 1: Immigrants arrived 1965-1970. Aged 30-45 in 1970 (50-65 in 1990)

Cohort 2: Immigrants arrived 1975-1980. Aged 30-45 in 1980 (50-65 in 2000)

Cohort 3: Immigrants arrived 1985-1990. Aged 30-45 in 1990 (50-65 in 2010)

Cohort 4: Immigrants arrived 1995-2000. Aged 30-45 in 2000 (40-55 in 2010) 

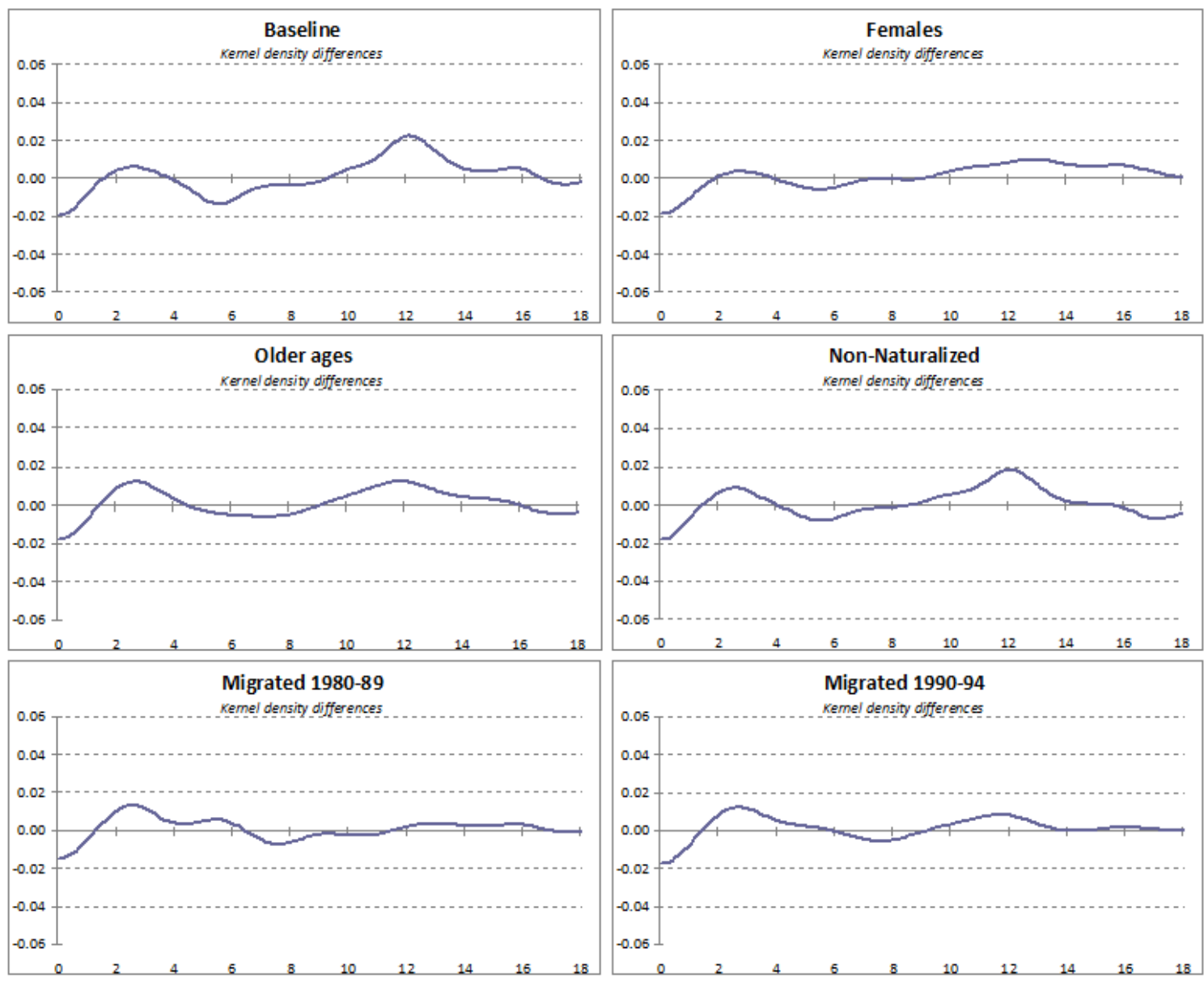

Figure 7a: Recent return migration educational selectivity.

2010-2000 Kernel density differences. MEXICO

The graph represent the difference between the 2010 and 2000 non-parametric kernel density estimations. A positive (negative) value means that a higher (lower) proportion of the individuals had that level of schooling in 2010 than in 2000 .

Baseline: Immigrants arrived 1995-2000, aged 30-55 in 2000.

Females: Female immigrants arrived 1995-2000, aged 30-55 in 2000.

Older ages: Immigrants arrived 1995-2000, aged 40-55 in 2000.

Non-Naturalized: Immigrants arrived 1995-2000, aged 30-55 in 2000 that have not received citizenship.

Migrated 1980-89: Immigrants arrived 1980-89, aged 40-55 in 2000.

Migrated 1990-94: Immigrants arrived 1990-94, aged 40-55 in 2000. 

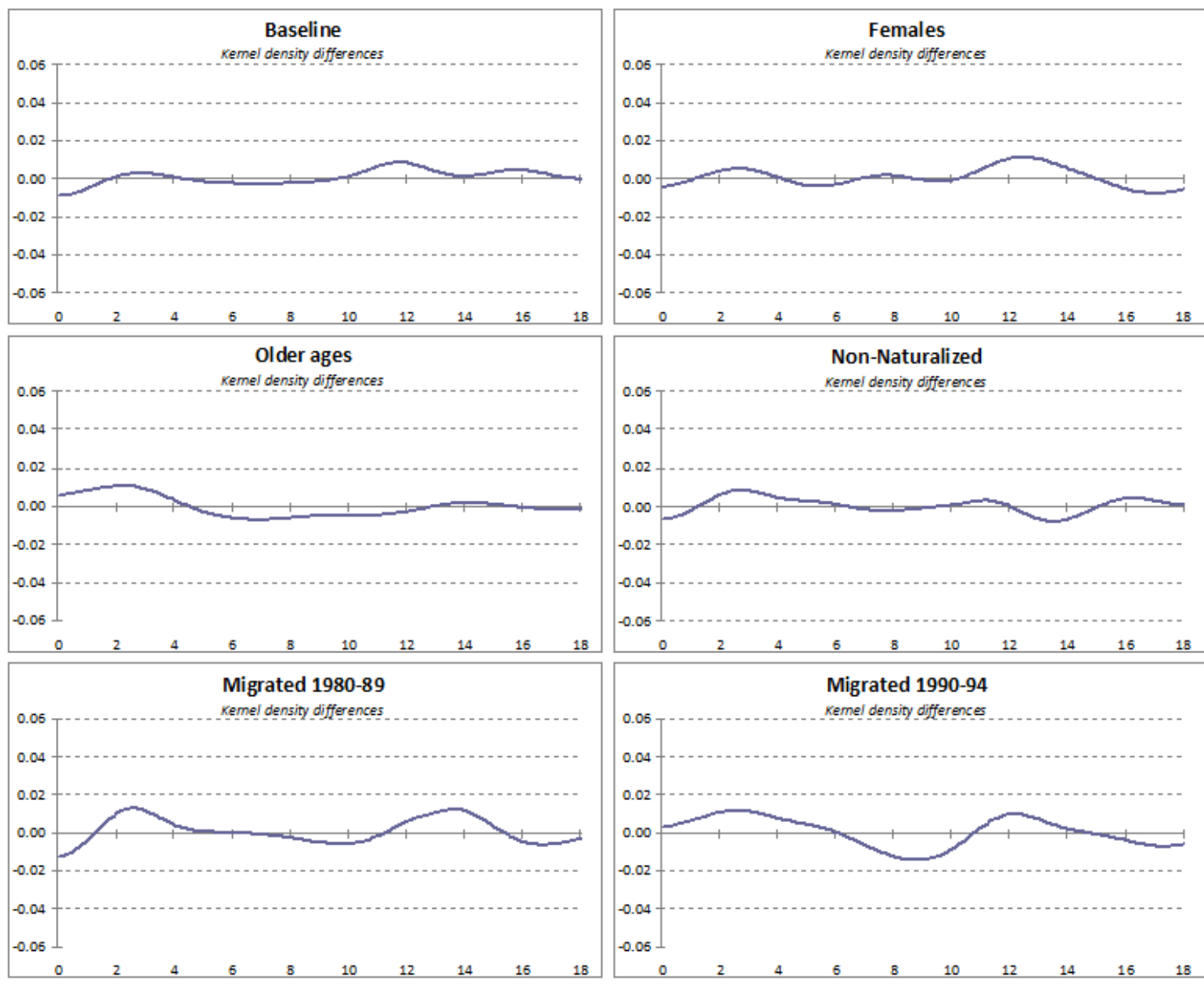

Figure 7b: Recent return migration educational selectivity. 2010-2000 Kernel density differences. CENTRAL AMERICA

The graph represent the difference between the 2010 and 2000 non-parametric kernel density estimations. A positive (negative) value means that a higher (lower) proportion of the individuals had that level of schooling in 2010 than in 2000 .

Baseline: Immigrants arrived 1995-2000, aged 30-55 in 2000.

Females: Female immigrants arrived 1995-2000, aged 30-55 in 2000.

Older ages: Immigrants arrived 1995-2000, aged 40-55 in 2000.

Non-Naturalized: Immigrants arrived 1995-2000, aged 30-55 in 2000 that have not received citizenship.

Migrated 1980-89: Immigrants arrived 1980-89, aged 40-55 in 2000.

Migrated 1990-94: Immigrants arrived 1990-94, aged 40-55 in 2000. 

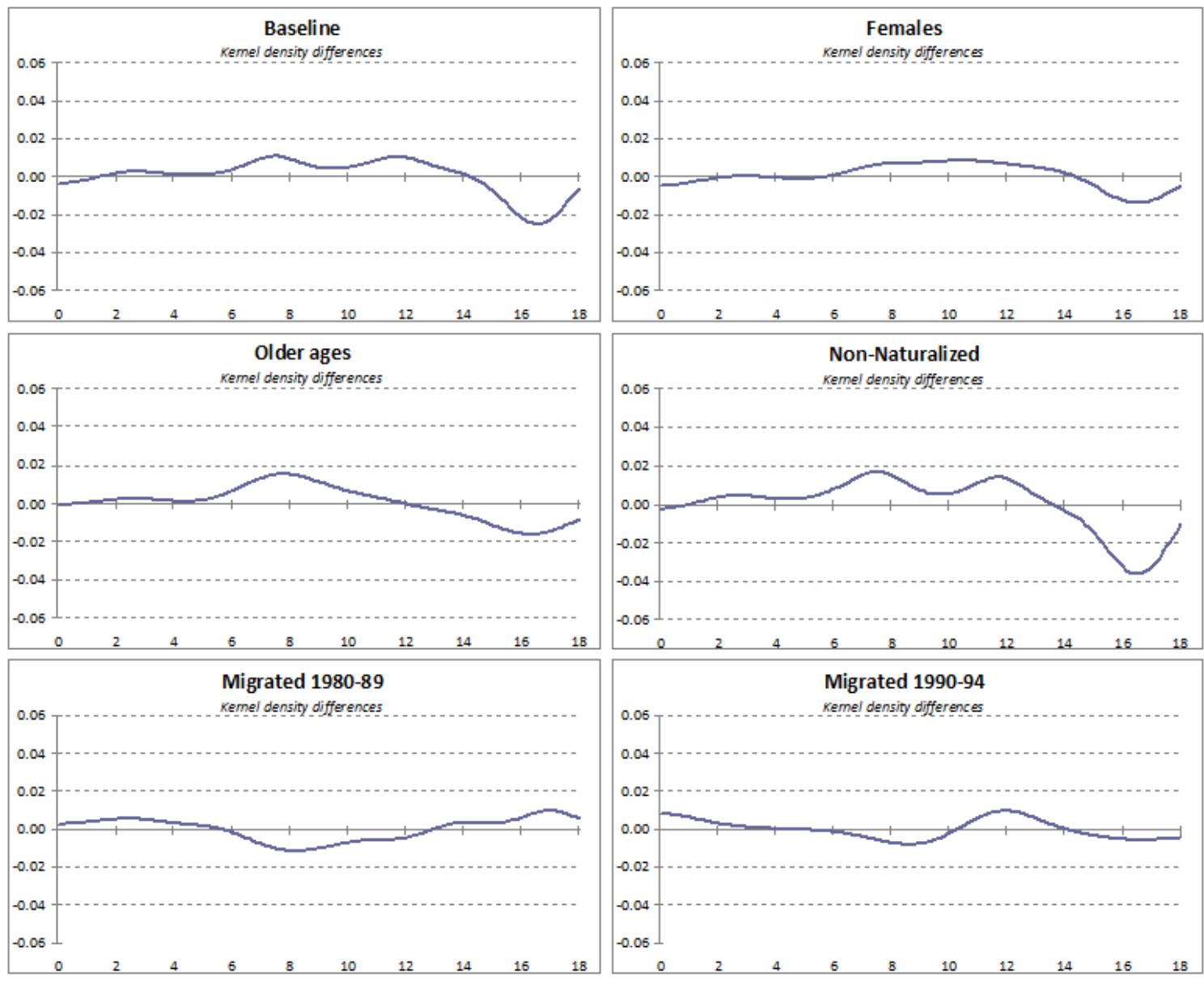

Figure 7c: Recent return migration educational selectivity.

2010-2000 Kernel density differences. CHINA

The graph represent the difference between the 2010 and 2000 non-parametric kernel density estimations. A positive (negative) value means that a higher (lower) proportion of the individuals had that level of schooling in 2010 than in 2000 .

Baseline: Immigrants arrived 1995-2000, aged 30-55 in 2000.

Females: Female immigrants arrived 1995-2000, aged 30-55 in 2000.

Older ages: Immigrants arrived 1995-2000, aged 40-55 in 2000.

Non-Naturalized: Immigrants arrived 1995-2000, aged 30-55 in 2000 that have not received citizenship.

Migrated 1980-89: Immigrants arrived 1980-89, aged 40-55 in 2000.

Migrated 1990-94: Immigrants arrived 1990-94, aged 40-55 in 2000. 

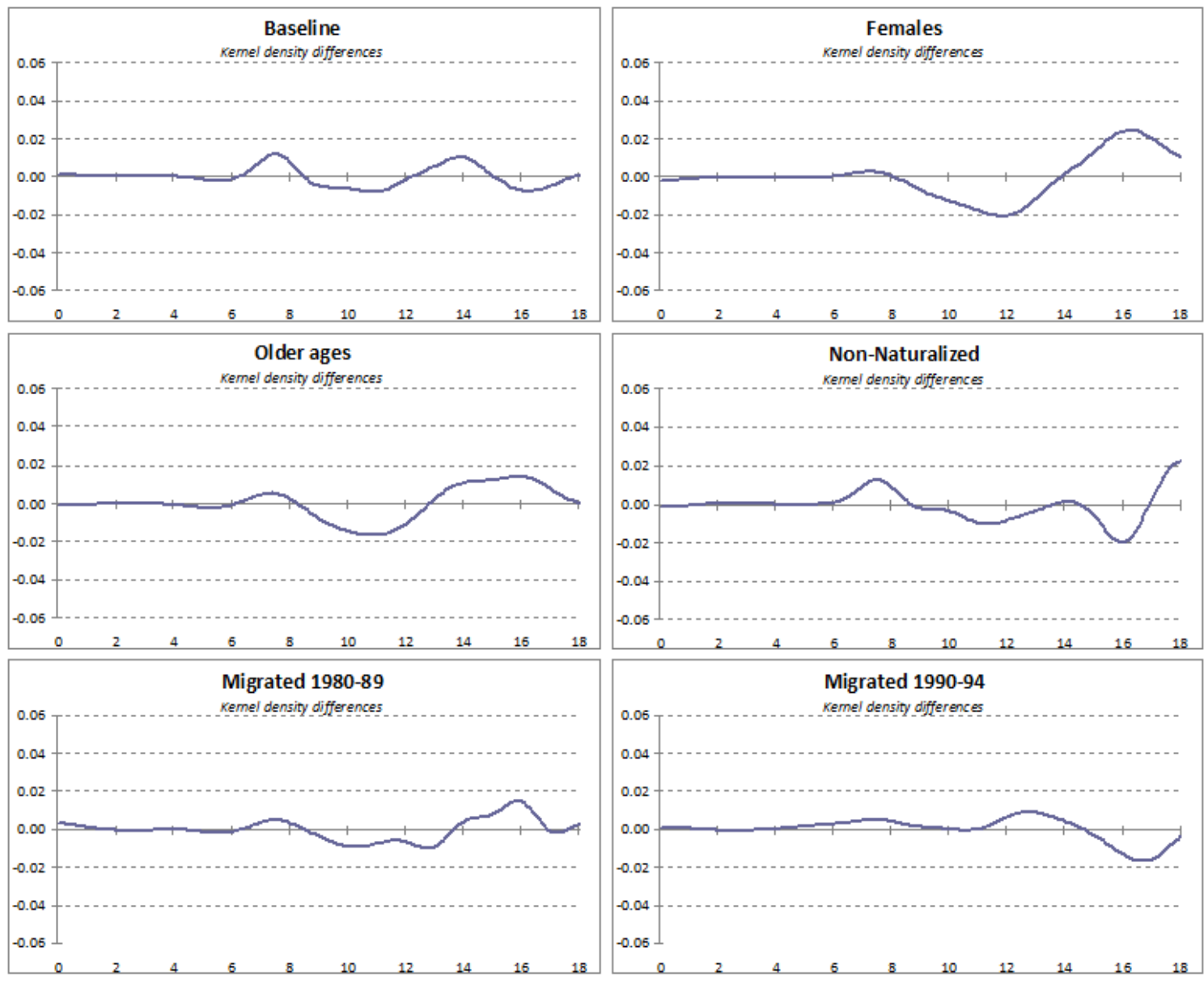

Figure 7d: Recent return migration educational selectivity.

\section{0-2000 Kernel density differences. INDIA}

The graph represent the difference between the 2010 and 2000 non-parametric kernel density estimations. A positive (negative) value means that a higher (lower) proportion of the individuals had that level of schooling in 2010 than in 2000 .

Baseline: Immigrants arrived 1995-2000, aged 30-55 in 2000.

Females: Female immigrants arrived 1995-2000, aged 30-55 in 2000.

Older ages: Immigrants arrived 1995-2000, aged 40-55 in 2000.

Non-Naturalized: Immigrants arrived 1995-2000, aged 30-55 in 2000 that have not received citizenship.

Migrated 1980-89: Immigrants arrived 1980-89, aged 40-55 in 2000.

Migrated 1990-94: Immigrants arrived 1990-94, aged 40-55 in 2000. 

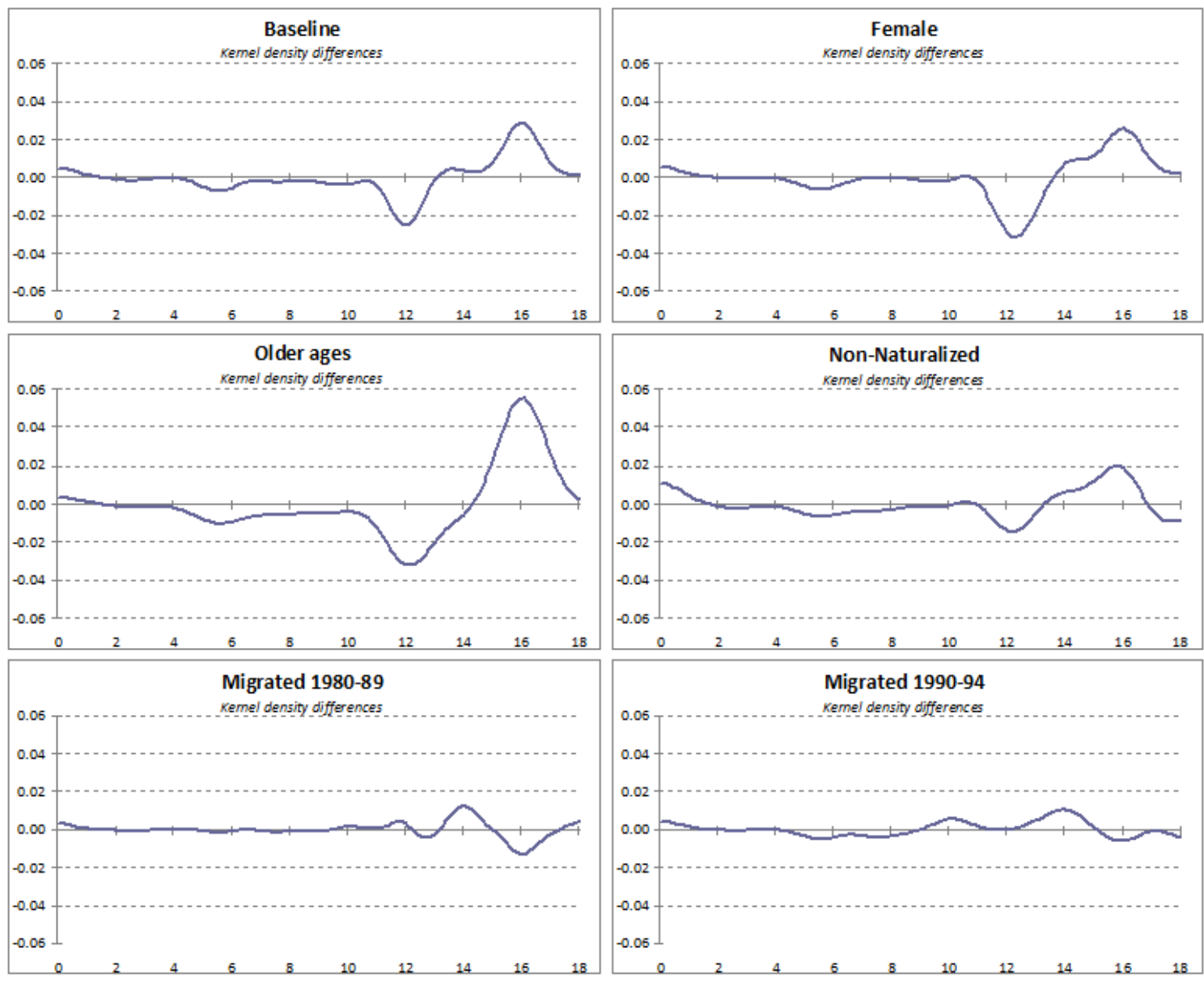

Figure 7e: Recent return migration educational selectivity.

\section{0-2000 Kernel density differences. PHILIPPINES}

The graph represent the difference between the 2010 and 2000 non-parametric kernel density estimations. A positive (negative) value means that a higher (lower) proportion of the individuals had that level of schooling in 2010 than in 2000 .

Baseline: Immigrants arrived 1995-2000, aged 30-55 in 2000.

Females: Female immigrants arrived 1995-2000, aged 30-55 in 2000.

Older ages: Immigrants arrived 1995-2000, aged 40-55 in 2000.

Non-Naturalized: Immigrants arrived 1995-2000, aged 30-55 in 2000 that have not received citizenship.

Migrated 1980-89: Immigrants arrived 1980-89, aged 40-55 in 2000.

Migrated 1990-94: Immigrants arrived 1990-94, aged 40-55 in 2000. 
Table A. 1: Number of observations for each country by year and cohort

\begin{tabular}{crrrrrrrrrrr}
\hline & & \multicolumn{10}{c}{ Country } \\
\cline { 2 - 11 } Cohort & Year & CAM & CAN & CHI & D.R. & ENG & GER & IND & ITA & MEX & PHI \\
\hline 1 & 1970 & 73 & 152 & 95 & 47 & 149 & 117 & 88 & 183 & 216 & 135 \\
1 & 1980 & 447 & 559 & 596 & 344 & 502 & 454 & 345 & 895 & 1,558 & 844 \\
1 & 1990 & 346 & 444 & 463 & 198 & 397 & 436 & 288 & 635 & 1,229 & 797 \\
\hline 2 & 1980 & 767 & 556 & 698 & 340 & 610 & 328 & 1,009 & 284 & 3,508 & 1,352 \\
2 & 1990 & 943 & 444 & 762 & 239 & 436 & 254 & 948 & 233 & 3,605 & 1,604 \\
2 & 2000 & 1,089 & 446 & 805 & 272 & 473 & 293 & 1,024 & 215 & 3,824 & 1,530 \\
\hline 3 & 1990 & 2,650 & 695 & 1,111 & 552 & 591 & 417 & 1,183 & 176 & 5,430 & 2,306 \\
3 & 2000 & 3,312 & 763 & 2,481 & 943 & 536 & 453 & 1,678 & 183 & 7,797 & 3,132 \\
3 & 2010 & 666 & 142 & 531 & 191 & 81 & 73 & 419 & 32 & 1,683 & 753 \\
\hline 4 & 2000 & 2,496 & 1,605 & 2,071 & 748 & 768 & 1,181 & 2,693 & 269 & 11,882 & 1,661 \\
4 & 2010 & 706 & 337 & 948 & 237 & 125 & 176 & 907 & 65 & 2,930 & 626 \\
\hline \hline
\end{tabular}

Source: U.S. 1970, 1980, 1990, and 2000 Census and 2010 American Community Survey 


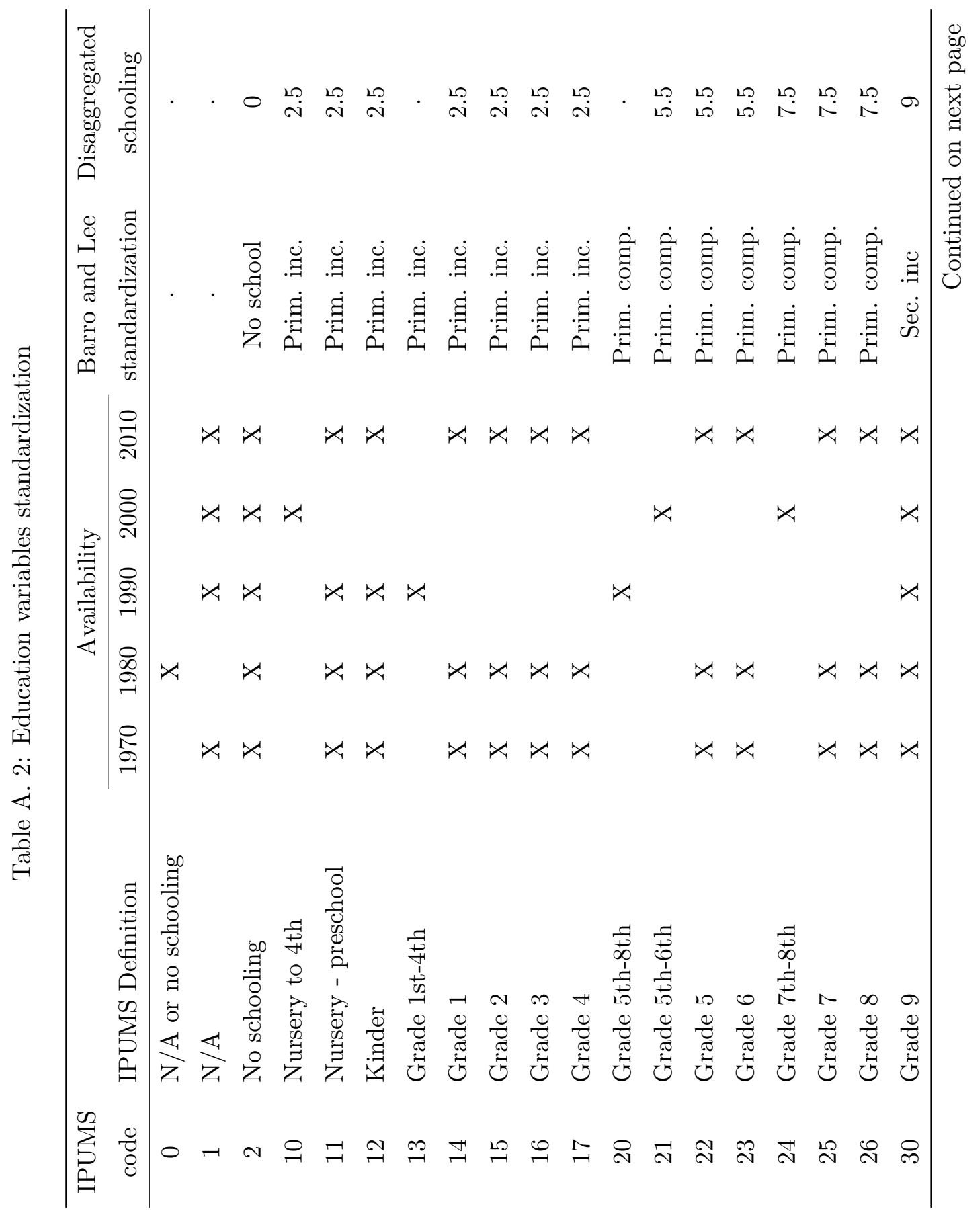




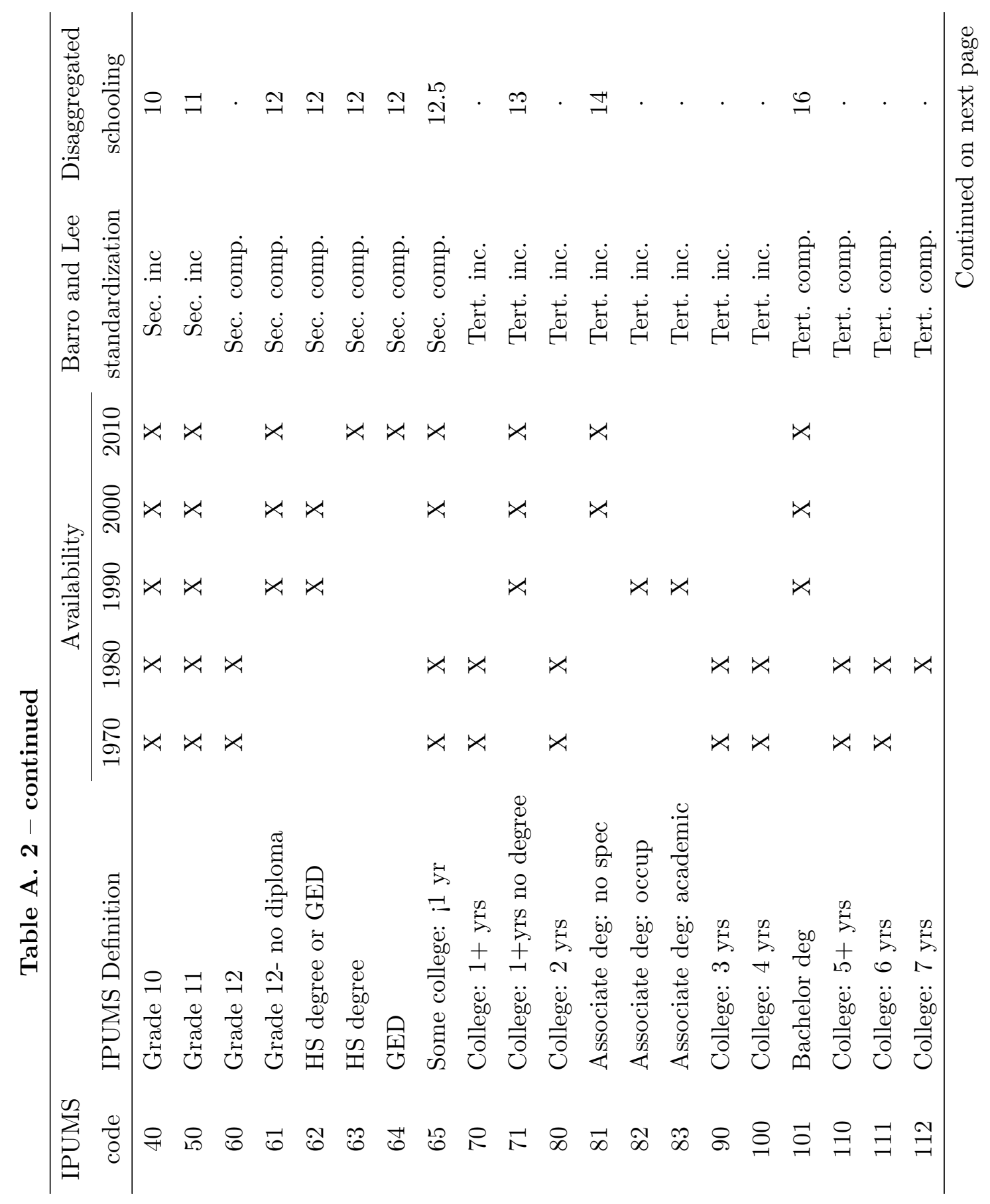




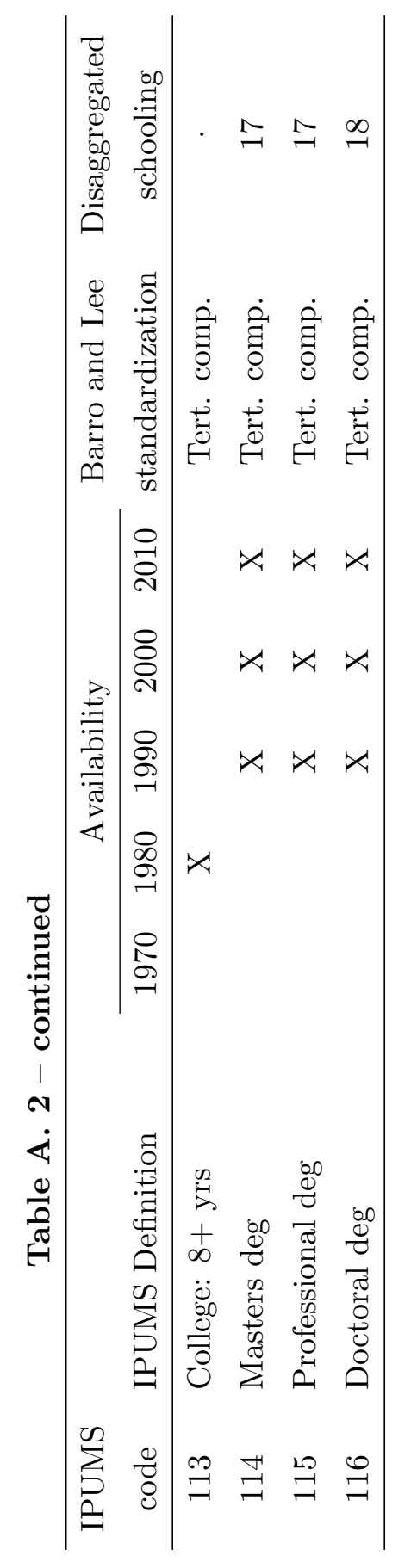

